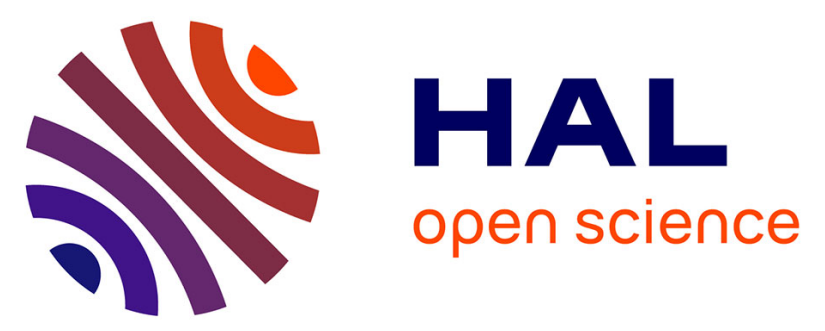

\title{
Movement of Amazon surface water from time-variable satellite gravity measurements and implications for water cycle parameters in land surface models
}

S.-C. Han, I.Y. Yeo, Doug Alsdorf, Paul Bates, Jean-Paul Boy, Hyungjun

Kim, Taikan Oki, Matthew Rodell

\section{To cite this version:}

S.-C. Han, I.Y. Yeo, Doug Alsdorf, Paul Bates, Jean-Paul Boy, et al.. Movement of Amazon surface water from time-variable satellite gravity measurements and implications for water cycle parameters in land surface models. Geochemistry, Geophysics, Geosystems, 2010, 11, pp.Q09007. 10.1029/2010GC003214 . hal-00747176

\author{
HAL Id: hal-00747176 \\ https://hal.science/hal-00747176
}

Submitted on 13 Oct 2021

HAL is a multi-disciplinary open access archive for the deposit and dissemination of scientific research documents, whether they are published or not. The documents may come from teaching and research institutions in France or abroad, or from public or private research centers.
L'archive ouverte pluridisciplinaire HAL, est destinée au dépôt et à la diffusion de documents scientifiques de niveau recherche, publiés ou non, émanant des établissements d'enseignement et de recherche français ou étrangers, des laboratoires publics ou privés.

$$
\text { Copyright }
$$




\title{
Movement of Amazon surface water from time-variable satellite gravity measurements and implications for water cycle parameters in land surface models
}

\author{
Shin-Chan Han \\ Planetary Geodynamics Laboratory, NASA Goddard Space Flight Center, 8300 Greenbelt Road, \\ Greenbelt, Maryland 20771,USA (shin-chan.han@nasa.gov) \\ Also at Goddard Earth Sciences and Technology Center, University of Maryland Baltimore County, \\ Baltimore, Maryland 21228, USA
}

In-Young Yeo

Department of Geography, University of Maryland, College Park, Maryland 20742, USA

\author{
Doug Alsdorf \\ School of Earth Sciences, Ohio State University, Columbus, Ohio 43210, USA
}

\section{Paul Bates}

School of Geographical Sciences, University of Bristol, Bristol BS8 1SS, UK

\section{Jean-Paul Boy}

Planetary Geodynamics Laboratory, NASA Goddard Space Flight Center, 8300 Greenbelt Road, Greenbelt, Maryland 20771, USA

Also at IPGS, UMR 7516, EOST, CNRS, UdS, F-67084 Strasbourg, France

\section{Hyungjun Kim and Taikan Oki}

Institute of Industrial Science, University of Tokyo, 4-6-1 Komaba, Meguro-ku, Tokyo 153-8505, Japan

\section{Matthew Rodell \\ Hydrological Sciences Branch, NASA Goddard Space Flight Center, Greenbelt, Maryland 20771, $U S A$}

[1] The large-scale observations of terrestrial water storage from GRACE satellites over the Amazon are analyzed with land surface model (LSM) outputs of runoff and soil moisture. A simple yet effective runoff routing method based on a continuity equation is implemented to model horizontal transport of surface water within the Amazon basin. The GRACE observations are analyzed separately for soil moisture and surface water storages (generated from runoff), relying on their distinct spatial patterns, being disperse for soil moisture and localized for surface water. Various effective velocities for storage transport are tested against the GRACE observations. When the model runoff is routed with an uniform velocity of $30 \mathrm{~cm} / \mathrm{s}$, the annual variation of the resulting surface water storage is generally found to be larger than the satellite measurements and ground gauge data by a factor of 1.5 or higher. The peak annual anomaly of surface water storage is observed around the midstream of the Amazon main stem. However, the runoff routing simulations present the peak amplitude consistently around the delta (downstream), unless the increasing velocity in a downstream region is used. As complements to the ground gauge data, the satellite observations 
provide unique 'spatial' information of water cycle parameters. Our analysis indicates possible shortcomings in the certain LSM mass transport scheme between atmosphere and land surface, particularly the production of too large seasonal variations in runoff (and maybe too little variations in evapotranspiration), and the dynamic characteristics of surface water transport within the Amazon basins.

Components: 8500 words, 11 figures.

Keywords: Amazon basin; hydrology; GRACE; time-variable gravity; land surface model; runoff routing.

Index Terms: 1217 Geodesy and Gravity: Time variable gravity (7223, 7230); 1223 Geodesy and Gravity: Ocean/Earth/ atmosphere/hydrosphere/cryosphere interactions $(0762,1218,3319,4550) ; 1836$ Hydrology: Hydrological cycles and budgets $(1218,1655)$.

Received 5 May 2010; Revised 8 July 2010; Accepted 21 July 2010; Published 17 September 2010.

Han, S.-C., I.-Y. Yeo, D. Alsdorf, P. Bates, J.-P. Boy, H. Kim, T. Oki, and M. Rodell (2010), Movement of Amazon surface water from time-variable satellite gravity measurements and implications for water cycle parameters in land surface models, Geochem. Geophys. Geosyst., 11, Q09007, doi:10.1029/2010GC003214.

\section{Introduction}

[2] The measurements of spatial and temporal variations of large-scale energy and water cycles over the Amazon are crucial to understand their interaction with atmosphere and feedbacks to the Earth's climate system. The water cycle parameters have rarely been shown based on observations alone at the scale of the river basin. Depending on the methods of implementing water transfer schemes in land surface models and on the spatial scales of the model outputs and observations, inferred water cycle parameters can differ substantially in magnitude and phase. While Shuttleworth [1988] and Costa et al. [2004] present ground measurements that indicate the annual cycle of evapotranspiration (ET) being higher in the dry season following the net radiation cycle over the Amazon, large-scale modeling results, such as those by Mocko and Sud [1998] and Werth and Avissar [2004], produce the opposite annual cycle in ET following the precipitation cycle. Substantial differences in the ET time series from various models are also evident especially over the Amazon basin [Ramillien et al., 2006]. A common practice to validate runoff simulations is to exploit the ground discharge measurements available at limited gauging stations around the world [Hunger and Döll, 2008; Kim et al., 2009; Zaitchik et al., 2010]. However, these measurements represent the lumped effect of all routed waters within a catchment basin. Thus, matching the model outputs to such measurements does not necessarily indicate valid simulations within the entire basin, especially where spatial patterns of water storage are concerned. Unlike those 'point- wise' measurements, space-borne data help to provide land water observations with improved spatial coverage that can be used complement data obtained from sparse gauging station networks.

[3] As a major application of the recent satellite measurements of time-variable mass redistribution on the Earth, the data from Gravity Recovery And Climate Experiment (GRACE) mission have been used to derive the total land water storage [Güntner, 2008, and references therein]. Syed et al. [2008] presents a comprehensive comparison between the GRACE water storage observations and the model storage outputs globally and in some major basins. Typically, the GRACE observations of terrestrial water storage changes are found to be larger in amplitude than the model storage including snow, canopy and soil storage, but neglecting the runoff-generated storage, especially over the Amazon basin.

[4] In this study, we analyze the GRACE observations of terrestrial water storage by splitting them into soil moisture and surface water storage (which represents integrated storage in rivers and floodplains, hereafter) components and by exploiting the runoff and soil moisture outputs from various land surface models (LSM). The massive volume in the Amazon discharge indicates that runoff is a significant factor in water storage change [Alsdorf et al., 2007]. Land surface models accounting for the vertical water fluxes ignore the time scale of water transport in rivers, streams, and floodplains to the ocean. The runoff data are often neglected in terrestrial water storage computation, which eventually yields model results that are smaller than the 
GRACE observations, as shown by Güntner [2008] and Syed et al. [2008]. The continuity equation and the river (upstream-downstream) network information can be used to derive surface water storage from runoff [Miller et al., 1994; Oki et al., 1999].

[5] Here we analyze outputs from the Global Land Data Assimilation System (GLDAS) [Rodell et al., 2004] driving the NOAH [Chen et al., 1996], Mosaic [Koster and Suarez, 1996], Variable Infiltration Capacity (VIC) [Liang et al., 1994], and Common Land Model (CLM, version 2) [Bonan, 1998] land surface models to interpret the GRACE total water storage observations. The concise description and comparison for each LSM parameterization are given by Rodell et al. [2004] and Kato et al. [2007], respectively.

[6] We explore particularly the annual cycles of fundamental hydrological parameters from various GLDAS/LSMs and routing schemes [Miller et al., 1994] and examine the observation of horizontal mass transport of surface water from the remnant of the GRACE observation after removing the soil moisture. Unlike other studies based on ground gauge data, we highlight the spatial patterns of the seasonal changes in storage and fluxes, because we now have satellite data with improved spatial coverage of total storage measurements. Important "spatial" information to validate LSMs that complements what one can get with gauge data is provided.

[7] In section 2, we present observations of the annual cycle in total land water storage from GRACE satellites. The appropriate spatial smoothing is determined to make high-resolution (such as $1^{\circ} \times 1^{\circ}$ or $\sim 110 \mathrm{~km}$ ) simulation outputs comparable to the large-scale, low-resolution $(\sim 400 \mathrm{~km})$ satellite observations. In section 3 , we formulate the water balance and continuity equations in a spectral domain, for the first time. By doing so, a straightforward scaling relationship between the annual (Fourier) spectrum of each hydrological parameter is established. A linear model between the runoff and surface water storage is introduced. In section 4, the river network and runoff routing is briefly described. In section 5, various effective velocities for runoff routing are tested against the GRACE observations. The distinct spatial patterns between the soil moisture storage and surface water storage are presented to highlight their importance for analyzing the satellite observations. Spatially varying velocity fields are also discussed. In section 6 , we discuss the comparison with the ground gauge measurements. Finally, in section 7, we summarize the results, provide the validation of various LSM outputs of soil moisture and runoff, and discuss implications for land surface modeling.

\section{Observations of Large-Scale Water Storage}

[8] The orbit perturbations measured as distance changes between two GRACE satellites represent gravitational perturbation caused by all kinds of mass re-distribution mostly on the Earth's surface. Such data are analyzed with respect to the a priori satellite orbits computed on the basis of various geophysical models. Temporal mass variations such as tides, non-tidal ocean mass, atmospheric mass, planetary bodies' attraction, and the steady state gravity field are typically included to compute the reference satellite orbits based on the respective models, for example, GGM02C [Tapley et al., 2005] for static mean gravity field and GOT4.7 (an update of Ray [1999]) for ocean tide. The non-gravitational forces (such as air drag) are corrected using the on-board accelerometer measurements. Therefore, the observed range-rate (with respect to the computed range-rate) allows one to infer 'total' terrestrial water storage as well as anomalous mass signals that are not completely removed with the applied geophysical models. In addition, we also include 3-hourly global soil moisture, snow and canopy water storage products at quarter degree grid cell resolution from GLDAS/NOAH in a priori force models to compute another set of precise reference orbits. With respect to those alternative orbits, the range-rate observations reflect the 'residual' terrestrial water storage because the range-rate effect of the modeled soil moisture and snow storage is removed a priori. We process five years $(2003-$ 2007) of GRACE inter-satellite range-rate data using the methods used by Han et al. [2008] for both cases; range-rate measurements without and with a priori correction of 3-hourly soil moisture and snow storage from GLDAS/NOAH.

[9] The range-rate data shown in Figure 1 present instantaneous perturbations in the distance between two GRACE satellites, measured by the K-Band Ranging (KBR) instrument during a high water season (from March to May) in year 2006. Three examples are presented when the satellites cross around the upstream $\left(290^{\circ} \mathrm{E}\right)$, midstream $\left(300^{\circ} \mathrm{E}\right)$, and downstream $\left(310^{\circ} \mathrm{E}\right)$ of the Amazon main stem. The root-mean square (RMS) of all overpass range-rate data is $0.53,0.78$, and $0.67 \mu \mathrm{m} / \mathrm{s}$, for the upstream, midstream, and downstream, respectively, 


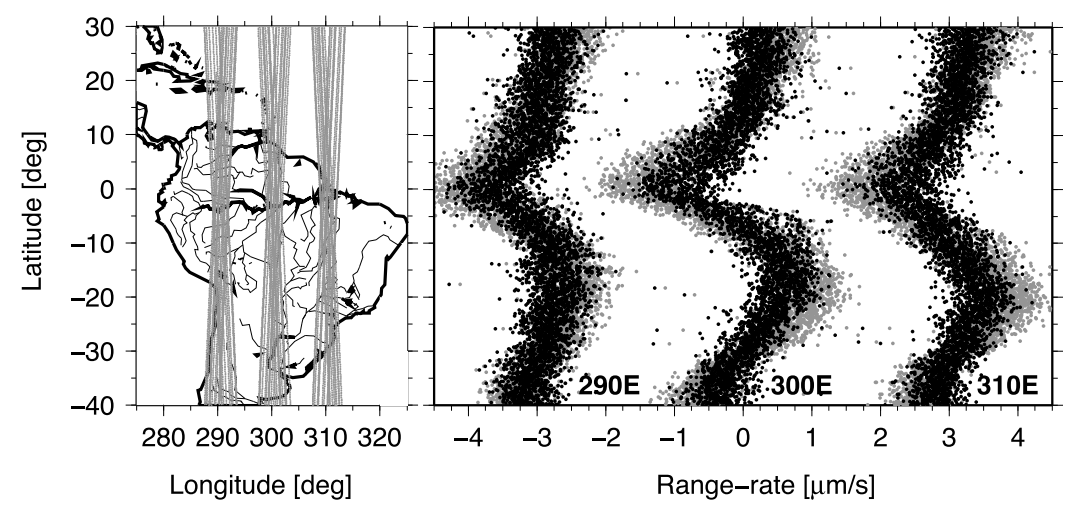

Figure 1. The satellite ground tracks during the high water season (March to May) in year 2006. Three examples when the satellites overpass the upstream, midstream and downstream of the main stem are shown. The KBR rate measurements are presented for each case with arbitrary constants added for plotting clarity. Gray dots indicate the perturbations yielded by the total water storage while black dots show the ones after removing the soil moisture storage component based on GLDAS/NOAH land surface model.

indicating the greatest mass variations around the midstream. After removing GLDAS/NOAH soil moisture from the measurements a priori [Han et al., 2009; Luthcke et al., 2006], the data residuals show the RMS variability of $0.36,0.52$, and $0.40 \mu \mathrm{m} / \mathrm{s}$, for the upstream, midstream, and downstream, respectively. The largest orbit perturbations (due to mass variations) are still found around the midstream.

[10] Using the localized analysis method of Han et al. [2008], the seasonal (annual and semi-annual) cycles of water storage in the entire Amazon and its vicinity areas are estimated at every $2^{\circ} \times 2^{\circ}$ block directly from the range-rate data (A resolution of $2^{\circ}$ does not necessarily represent the GRACE's spatial sensitivity. The actual resolution is discussed later). Two sets of seasonal water storage variations are estimated from GRACE data: total water storage and residual water storage excluding GLDAS/ NOAH soil moisture storage. Figure 2 presents the amplitude and harmonic coefficients of the annual cycle of the time series at each grid. It highlights the spatial patterns of the seasonal changes (in lieu of the temporal pattern at several stations), which will be used to validate and assess the overall model outputs throughout the entire basins. The time series at every grid is represented as $y(t)=$ $C \cos (\omega t)+S \sin (\omega t)$, where $C$ and $S$ are the coefficients given in Figure 2, $\omega$ is an angular frequency in $\mathrm{rad} /$ day such as $2 \pi / 365.25$, and $t$ is the day of the year. The second harmonic associated with a semiannual frequency is several factors to an order of a magnitude smaller than the primary harmonic of the annual frequency. These seasonal harmonic components are extracted directly from five years of GRACE data just like estimating tidal (roughly daily and sub-daily) harmonics from the raw data as in the work by Han et al. [2008]. While the first estimates shown in Figure 2 (top) indicate the total terrestrial water storage, the second estimates depicted in Figure 2 (bottom) are the residual storage variations excluding GLDAS/NOAH soil moisture and snow storage. The broad-scale anomalies spread
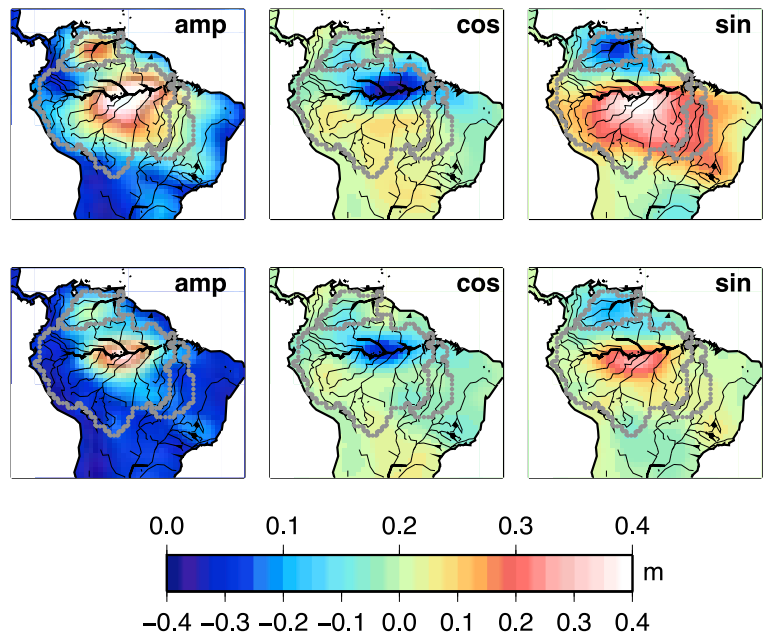

Figure 2. (top) Amplitude, cosine (in-phase), and sine (quadrature) components of the annual mass redistribution observed by GRACE KBR instrument. (bottom) Same as in Figure 2 (top) but after removing 3-hourly soil moisture storage from GLDAS/NOAH. The annual time series is defined by $y(t)=C \cos (\omega t)+S \sin (\omega t)$ where $t$ is day of the year, $\omega$ is the one cycle per year frequency, and $C$ and $S$ and the amplitude $\sqrt{C^{2}+S^{2}}$ are shown in Figure 2. The color scale shows the ranges for amplitude $(0-0.4 \mathrm{~m})$ and for cosine and sine components $(-0.4-0.4 \mathrm{~m})$. 
over the southern areas of the Amazon basin (upstream of the southern tributaries), in Figure 2 (top), are consistent with the GLDAS/NOAH soil moisture outputs, so that the residuals in Figure 2 (bottom) show little variation. However, the focused anomalies with greater amplitude appear around the Amazon main stem are supposed to be associated with surface water storage flowing eventually to the ocean. It is not modeled in the GLDAS/LSM. The soil moisture and surface water storage are distinct in spatial pattern as well as the response to the inter-satellite range-rate as also noted by Han et al. [2009].

[11] The difference between those GRACE solutions (Figures 2 (top) and 2 (bottom)) is compared to the annual cycle of the GLDAS/NOAH soil moisture storage, but after applying the low-pass filter (i.e., spatial smoothing) to the models by truncating the spherical harmonic degrees and orders to 50 (corresponding to a spatial resolution of $400 \mathrm{~km}$ ). This experiment indicates the most plausible level of spatial smoothing we have to apply to the highresolution model outputs prior to any comparison with the low-resolution GRACE measurements.

\section{Runoff Routing: Continuity Equation in a Spectral Domain}

[12] In this section, we develop an efficient algorithm to implement continuity equation for runoff routing and thus for computing surface water storage. Unlike the time stepping method, we formulate simple linear equations between runoff and surface water storage in a spectral domain, which deliver the equivalent results. The fundamental laws implemented in a land surface model are water (mass) and energy (radiation and heat) balance. Numerical models are designed to solve those equations at each time step and at every grid cell with given atmospheric forcing data and to produce runoff, evapotranspiration (ET), and soil moisture and snow storage by partitioning the input precipitation on the basis of various physical schemes for mass and energy transport. The water balance equation can be written as follows [Hansen et al., 1983; Pitman, 2003]:

$$
\frac{\partial s(t)}{\partial t}=p(t)-e(t)-q(t),
$$

where $p(t)$ is precipitation including rain and snow, $e(t)$ is ET including soil and canopy evaporation and transpiration, $q(t)$ is surface (non-infiltrating) and subsurface (base flow) runoff, and $s(t)$ is total storage including soil moisture, snow storage, and groundwater storage. To compute the storage in the rivers/channels and floodplains generated by the LSM runoff (named as source runoff by Miller et al. [1994]) at each cell, the continuity equation can be used [Miller et al., 1994; Oki et al., 1999]. Its change is written as $\frac{\partial h(t)}{\partial t}=q_{\text {in }}(t)-q_{\text {out }}(t)+q(t)$, where the runoff $q(t)$ (with a physical dimension of length per time) is given by the LSM while the surface water storage $h(t)$ (with a physical dimension of length, i.e., simply height) is derived by routing $q(t)$ within the entire river network. $q_{\text {out }}(t)$ is the rate of surface water storage leaving the current cell to the immediate neighboring cell in a downstream direction. The outflow is proportional to the surface water storage such as $q_{\text {out }}(t)=\frac{u}{L} h(t)$ with given flow velocity, $u$, and distance to the downstream cell, $L$. (Note that $h / L$ is simply a cross-sectional area per unit cell area and thus $q_{o u t}$ is discharge per unit cell area in length per time). Also $L / u$ is often addressed as streamflow residence time [Costa and Foley, 1997; Coe, 2000]. $q_{\text {in }}(t)$ is the sum of fluxes contributing from all neighboring upstream cells connected to the present cell in a dendritic network. That is, $q_{\text {in }}(t)=\sum q_{\text {out }, i}(t)=$ $\sum_{i} \frac{u_{i}}{L} h_{i}(t)$, where the upstream cell is denoted with the index $i$. Putting all in one equation, the following expression can be obtained for surface water storage:

$$
\frac{\partial h(t)}{\partial t}+\frac{u}{L} h(t)-\sum_{i} \frac{u_{i}}{L_{i}} h_{i}(t)=q(t) .
$$

It implies that the runoff at the present cell is related to the surface water storages at the present and immediate upstream cells. In other words, surface water storage within a basin is derived solely by runoff generated from the LSM.

[13] A typical way to solve equation (2) is a time stepping method. Alternatively, it can be solved more directly and easily in a spectral domain by exploiting the fact that the time-derivative is nothing but a scaling operation in a frequency domain. We start by re-writing the water balance equation in a spectral domain as follows:

$$
\begin{gathered}
\omega_{j} S_{j}^{s}=P_{j}^{c}-E_{j}^{c}-Q_{j}^{c}, \\
-\omega_{j} S_{j}^{c}=P_{j}^{s}-E_{j}^{s}-Q_{j}^{s},
\end{gathered}
$$

where $P_{j}^{c}$ and $P_{j}^{s}$ are the Fourier coefficients of precipitation time series associated with a frequency $\omega_{j}$ such that $p(t)=\sum_{j} P_{j}^{c} \cos \left(\omega_{j} t\right)+P_{j}^{s} \sin \left(\omega_{j} t\right), E_{j}^{c}$ 
and $E_{j}^{s}$ are those of ET, $Q_{j}^{c}$ and $Q_{j}^{s}$ are those of runoff, and finally $S_{j}^{c}$ and $S_{j}^{s}$ are those of total storage. Equations (3a) and (3b) hold at each grid. The following shows a matrix-vector expression including all grid cells within a river basin:

$$
\mathbf{D}_{j} \mathbf{S}_{j}=\mathbf{P}_{j}-\mathbf{E}_{j}-\mathbf{Q}_{j},
$$

where $\mathbf{D}_{j}$ is a diagonal matrix made up of either $\omega_{j}$ or $-\omega_{j}$ and $\mathbf{P}_{j}, \mathbf{E}_{j}, \mathbf{Q}_{j}$, and $\mathbf{S}_{j}$ are the vectors including the Fourier coefficients of $\omega_{j}$ at each cell (two per cell for cosine and sine harmonic components of each frequency). Similarly, the continuity equation can be expressed as follows:

$$
\begin{gathered}
\omega_{j} H_{j, 0}^{s}+\frac{u_{0}}{L_{0}} H_{j, 0}^{c}-\sum_{i} \frac{u_{i}}{L_{i}} H_{j, i}^{c}=Q_{j, 0}^{c}, \\
-\omega_{j} H_{j, 0}^{c}+\frac{u_{0}}{L_{0}} H_{j, 0}^{s}-\sum_{i} \frac{u_{i}}{L_{i}} H_{j, i}^{s}=Q_{j, 0}^{s},
\end{gathered}
$$

where the subscript 0 and $i$ indicate the present cell and neighboring upstream cells, respectively. $H_{j}^{c}$ and $H_{j}^{s}$ are the Fourier coefficients of surface water storage associated with a frequency $\omega_{j}$. Unlike the water balance equation, each cell is laterally connected through flow direction. Equation (4a) and (4b) can be solved by forming a matrix-vector expression for each basin as follows:

$$
\mathbf{G}_{j} \mathbf{H}_{j}=\mathbf{Q}_{j},
$$

where a matrix $\mathbf{G}_{j}$ depends on the river connectivity and is constructed with flow velocity $u_{i}$, downstream distance between two connected cells $L_{i}$, and frequency $\omega_{j}$. It is a sparse (but full) matrix and its diagonal component is $u_{0} / L_{0}$ of the respective cell. The number of nonzero off-diagonal components at each row is equal to the number of upstream cells connected to the respective cell. In all the cases for large river basins we have tested, the matrix $\mathbf{G}_{j}$ is always invertible (full-ranked) without any numerical instability. The matrix $\mathbf{G}_{j}$ is constructed separately for each river basin and for each frequency, because two different basins do not interact for flow routing process and the spectra of two different frequencies do not interfere. The surface water storage spectrum is obtained simply by $\mathbf{H}_{j}=\mathbf{G}_{j}^{-1} \mathbf{Q}_{j}$ at each frequency and at each basin. The time series is re-constructed simply by an inverse Fourier transform of $\mathbf{H}_{j}$ including the spectra of all frequencies. That is, the surface water storage is obtained simply by converting the runoff data with the inverse of the matrix $\mathbf{G}_{j}$.

[14] By virtue of the orthogonality between the harmonic functions, it can be deduced that surface water storage associated with a frequency of $\omega_{j}$ originates solely from the runoff of the same frequency. That is, the annual variations of surface water storage stem exclusively from the annual variations of (source) runoff from LSM. The matrix $\mathbf{G}_{j}$ accounts for complicated differences in phase lag and amplitude of the time series between the LSM source runoff and surface water storage. For the same reason, the annual variations in ET, runoff, and soil moisture are due to the annual variations in precipitation. Therefore, the annual variations of water storage observed from GRACE can be analyzed on the basis of the annual cycle of each hydrological component. For example, the GRACE observations shown in Figure 2 can be compared with the sum of soil moisture storage $\left(\mathbf{S}_{j}\right)$ and surface water storage $\left(\mathbf{H}_{j}\right)$, i.e., $\mathbf{S}_{j}+\mathbf{G}_{j}^{-1} \mathbf{Q}_{j}$, when $\omega_{j}$ is an annual frequency and $\mathbf{S}_{j}$ and $\mathbf{Q}_{j}$ are the annual components of the LSM outputs. The results from the new spectral domain method are shown to agree with the results from an independent time stepping method for runoff routing as described by Oki et al. [1999].

[15] Figure 3 presents hydrological parameter outputs from various GLDAS LSMs including NOAH, CLM, Mosaic, and VIC. The daily averaged time series for a $1^{\circ} \times 1^{\circ}$ global grid are analyzed and the Fourier spectrum at each cell is computed. The spectrum of annual frequency for precipitation $\mathbf{P}_{j}$, ET $\mathbf{E}_{j}$, runoff $\mathbf{Q}_{j}$, and total storage rate $\pm \omega_{j} \mathbf{S}_{j}$ are presented for their amplitude, cosine and sine components. The respective time series averaged over the Amazon basin are also shown. Those are computed from 5 years of the time series corresponding to the period used for the GRACE data analysis. The water balance at the annual frequency can be verified by using equations (3a) and (3b). Although all GLDAS LSMs are forced with the same CMAP data for precipitation input [Rodell et al., 2004], there are substantial differences found

Figure 3. Amplitude, cosine and sine components of the annual variations for water cycle parameters from various GLDAS/LSMs including (a) CLM, (b) Mosaic, (c) NOAH, and (d) VIC. Precipitation (P), Evapotranspiration (ET), runoff $(\mathrm{Q})$, and temporal change in total storage $(\mathrm{dS} / \mathrm{dt})$ are shown. The time series of each parameter averaged in the Amazon basin are presented. The color scale shows the ranges for amplitude $(0-5 \mathrm{~mm} /$ day $)$ and for cosine and sine components $(-5-5 \mathrm{~mm} /$ day $)$. 
a
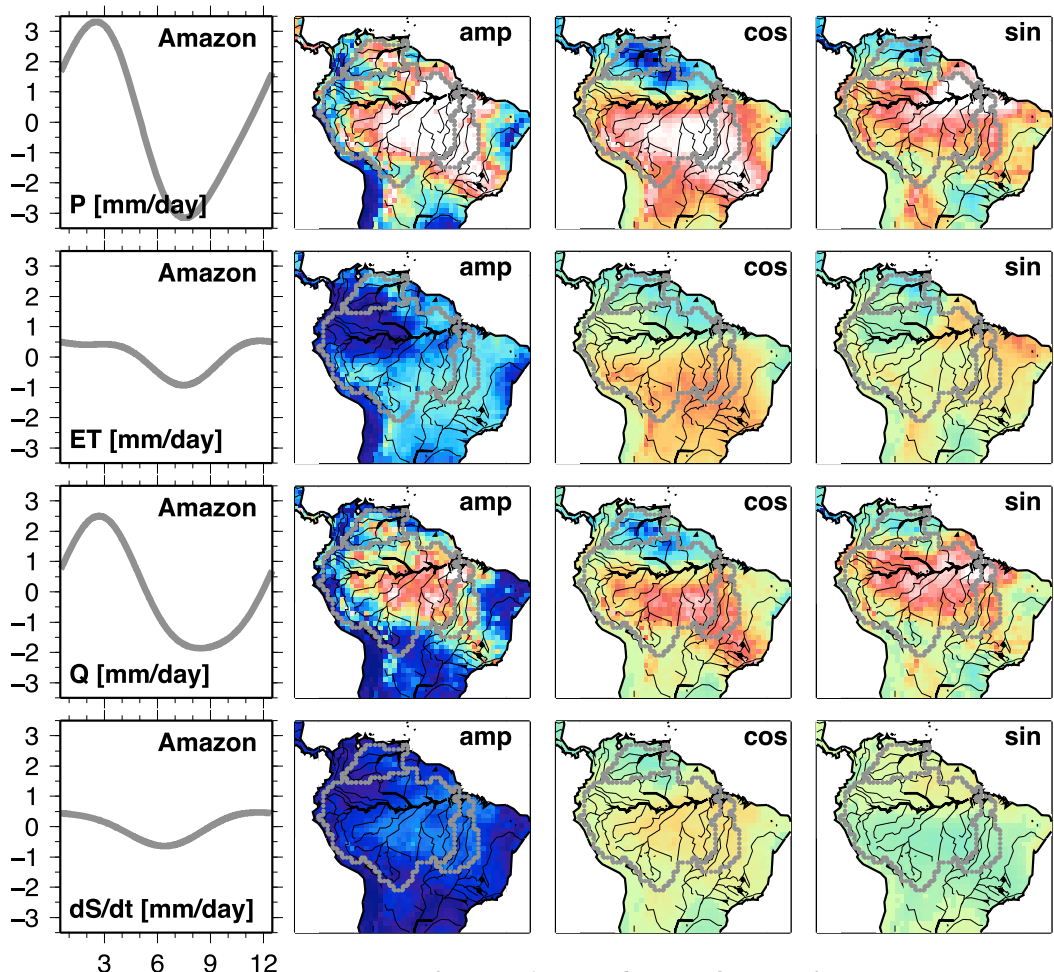

$\begin{array}{llll}3 & 6 & 9 & 12\end{array}$

GLDAS/CLM

b
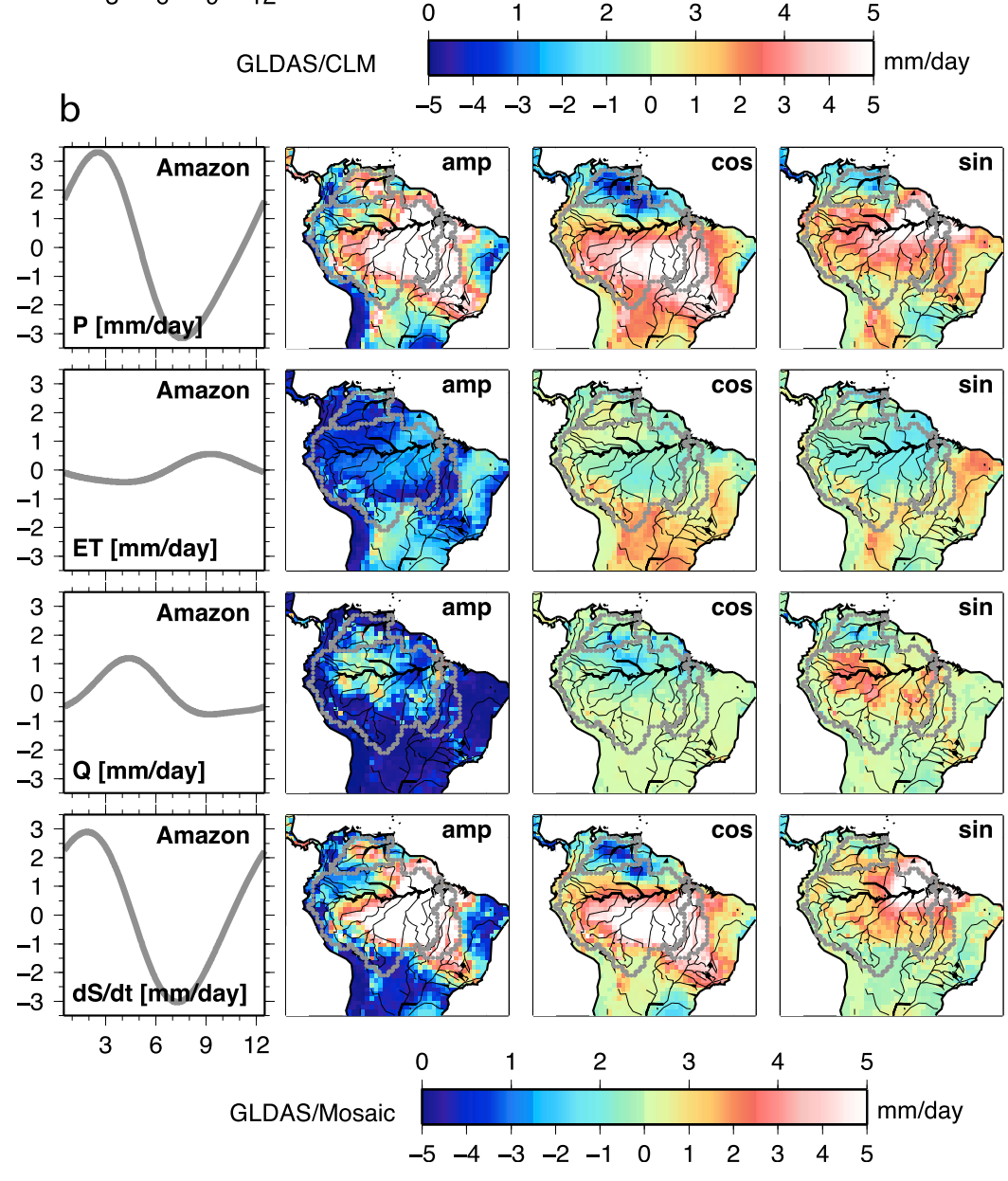

Figure 3 

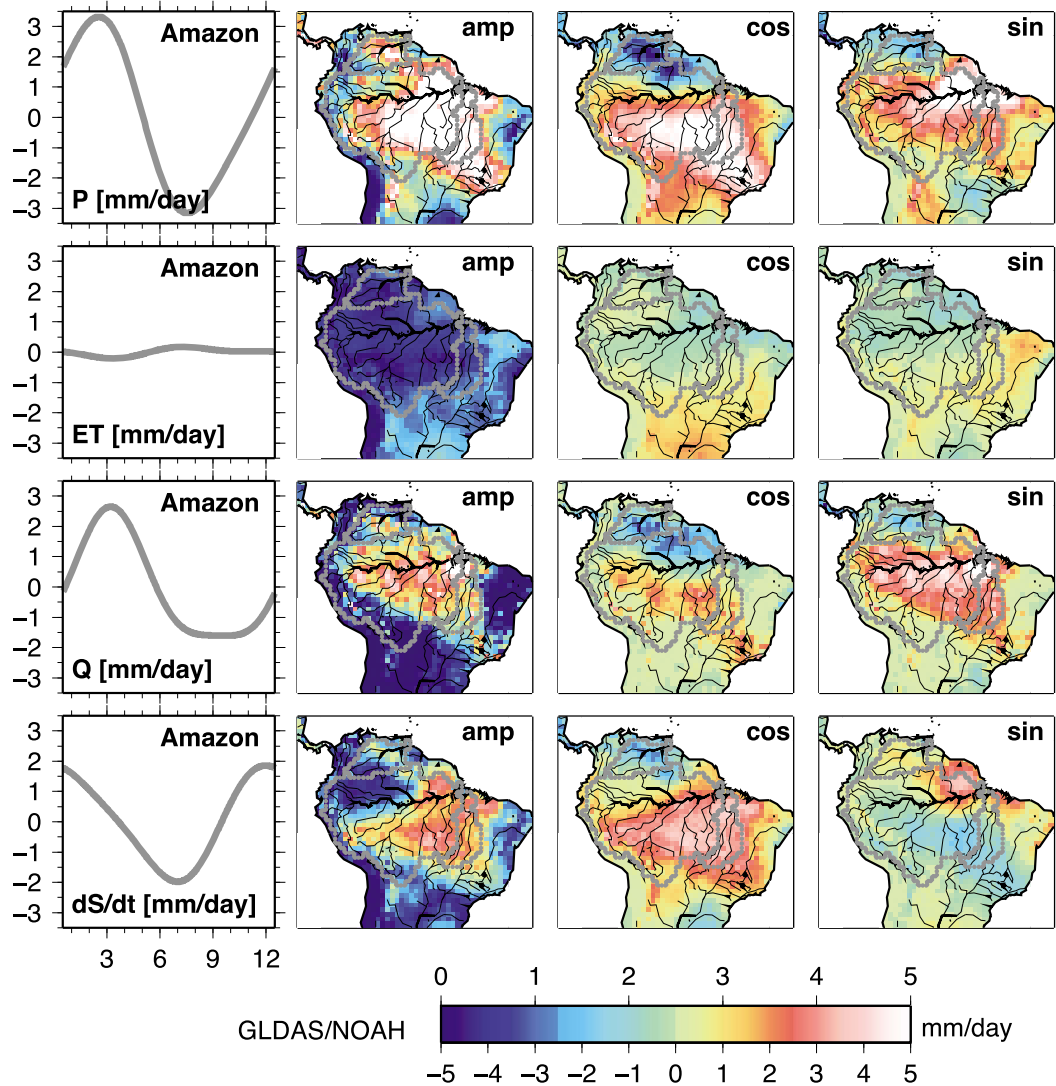

d
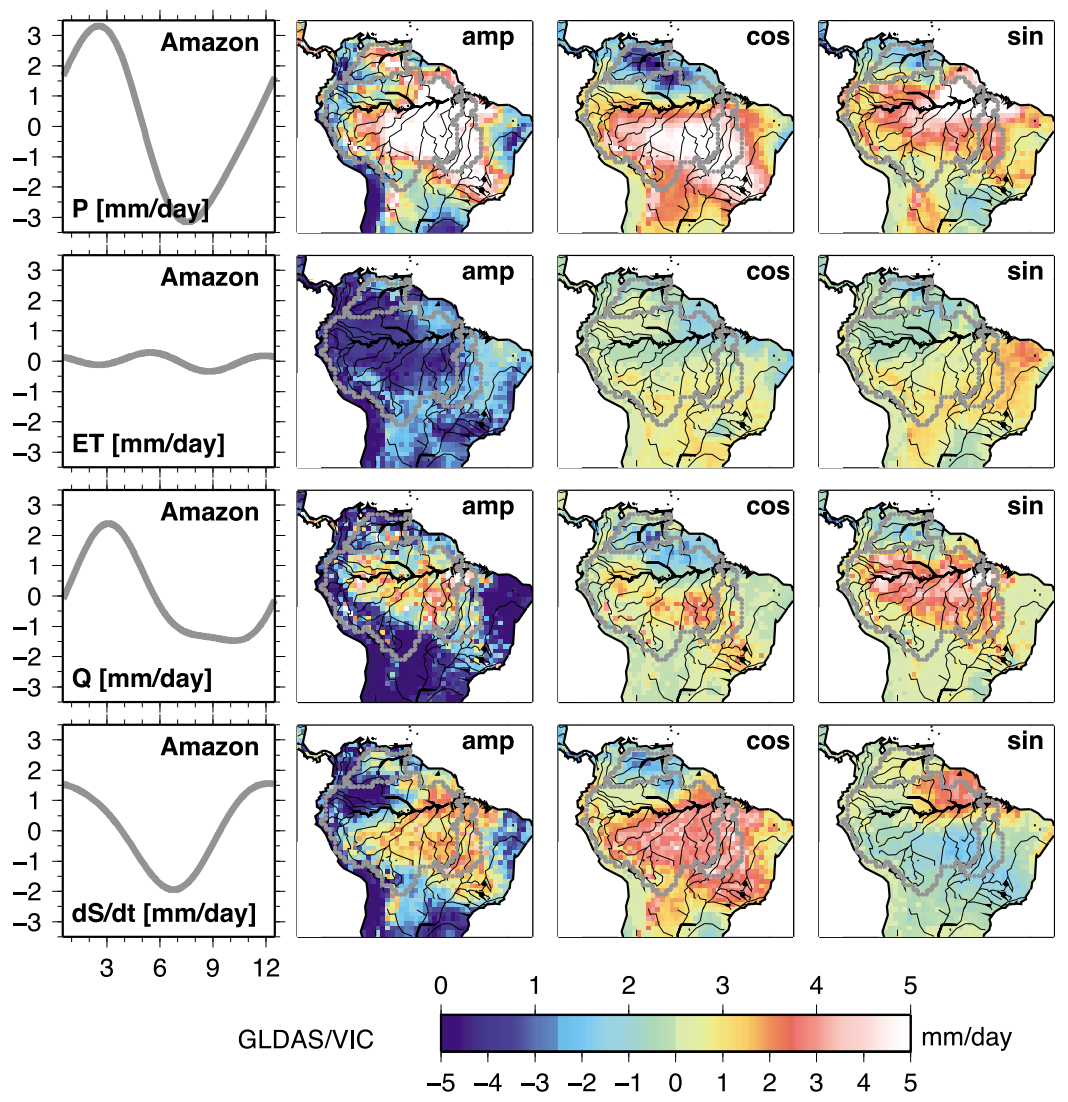

Figure 3. (continued) 
among various LSM outputs. In all LSMs, the annual variation of ET is quite small $(0.2-0.3 \mathrm{~mm} /$ day $)$ except CLM. The annual variation of Mosaic runoff is significantly smaller than the ones from other LSMs, consequently yielding larger annual variations in soil moisture rate. For Mosaic, most of the annual rainfall goes into the soil moisture. On the contrary, CLM shows very small annual variation in soil moisture rate. The annual variation in precipitation is partitioned mostly into runoff (and ET to a lesser extent).

\section{Surface Water Storage Computed From Runoff}

[16] It is total land water storage from various models that can be compared to the GRACE observations after applying the smoothing commensurate with the limited spatial resolution of the satellite observations. The terrestrial water storage is computed by combining soil moisture $\left(\mathbf{S}_{j}\right)$ obtained directly from the LSM and surface water storage $\left(\mathbf{H}_{j}\right)$ independently computed by routing the surface and sub-surface runoff $\left(\mathbf{Q}_{j}\right)$ within the river basin provided with the river network information. We use the Total Runoff Integrating Pathways (TRIP) model [Oki et al., 1999] to define the routing direction based on topography and the connection between the upstream-downstream river cells. In addition to the river network, the effective velocity as described by Miller et al. [1994] needs to be specified to construct the routing matrix $\mathbf{G}_{j}$ at each cell within the basin. The effective velocity is often interpreted as an integrated mean velocity of rainwater traveling from the surface soil layer to the river mouth through various paths, influenced also by shallow groundwater movement [Oki et al., 1999]. Practically, it could be fixed as a constant [Miller et al., 1994] for large scale modeling or be a variable following the topographic gradient and other physical factors such as bottom friction and hydraulic radius [Costa and Foley, 1997; Hagemann and Dümenil, 1997; Coe, 2000; Olivera et al., 2000]. Han et al. [2009] also highlights the importance of temporal variations in the effective velocity.

[17] Figure 4 presents an example of an annual surface water storage spectrum computed from GLDAS/NOAH runoff outputs with an effective velocity of $30 \mathrm{~cm} / \mathrm{s}$ (representing averaged value for in-channel and overland flow velocities) throughout the basin. Three major river basins (Amazon, Orinoco, and Tocantins) and the flow direction vectors taken from TRIP are shown. By modeling the horizontal mass transport with the runoff anomalies in each cell, we find the surface water storage anomalies converge along the rivers. The computed surface water storage is focused on narrow areas including rivers, channels, and floodplains with larger amplitudes, while the soil moisture storage is spread broadly with smaller magnitudes. Those distinct spatial patterns of both storage components are useful to analyze the GRACE observations of total storage and validate the LSM outputs of soil moisture and runoff. The annual cycle of such surface water storage is exclusively caused by the annual cycle of runoff output from LSM, as implied by the continuity equation in a spectral domain. The runoff routing simulations performed at a $1^{\circ} \times 1^{\circ}$ resolution are then smoothed to the resolution of $400 \mathrm{~km}$ in order to be commensurate with the spatial resolution of GRACE observations. The various model combinations of runoff and soil moisture storage from four GLDAS LSMs with variable velocities are analyzed. We discuss the quality of LSM simulations in producing annual changes of runoff and soil moisture storage on the basis of GRACE observations.

\section{Analysis of the Annual Cycle in Soil Moisture Storage and Runoff From LSM}

[18] The differences between the soil moisture models and the GRACE observations of total water storage reflect the surface water storage that is not currently modeled in the GLDAS/LSMs. Any error in the soil moisture model directly affects the residual storage to be interpreted as surface water storage in addition to the GRACE observational noise. Currently, the depths of the simulated soil zone are $3.4 \mathrm{~m}, 3.5 \mathrm{~m}, 2.0 \mathrm{~m}$, and $1.9 \mathrm{~m}$ for CLM, Mosaic, NOAH, and VIC, respectively. The groundwater storage, not modeled currently in any of GLDAS/LSMs, also gives the additional uncertainty. With these caveats, the surface water storages computed from the runoff outputs of various LSMs are then compared with those residual storages obtained from GRACE observations and soil moisture models. With the advantage of large spatial coverage from satellite data, albeit with limited resolution due to the sensitivity of the onboard instrument and to the orbital altitude, the overall assessment of the LSM runoff products and routing simulation throughout the basin is possible.

[19] The first and second columns of Figure 5 show the amplitude and annual spectrum components of 

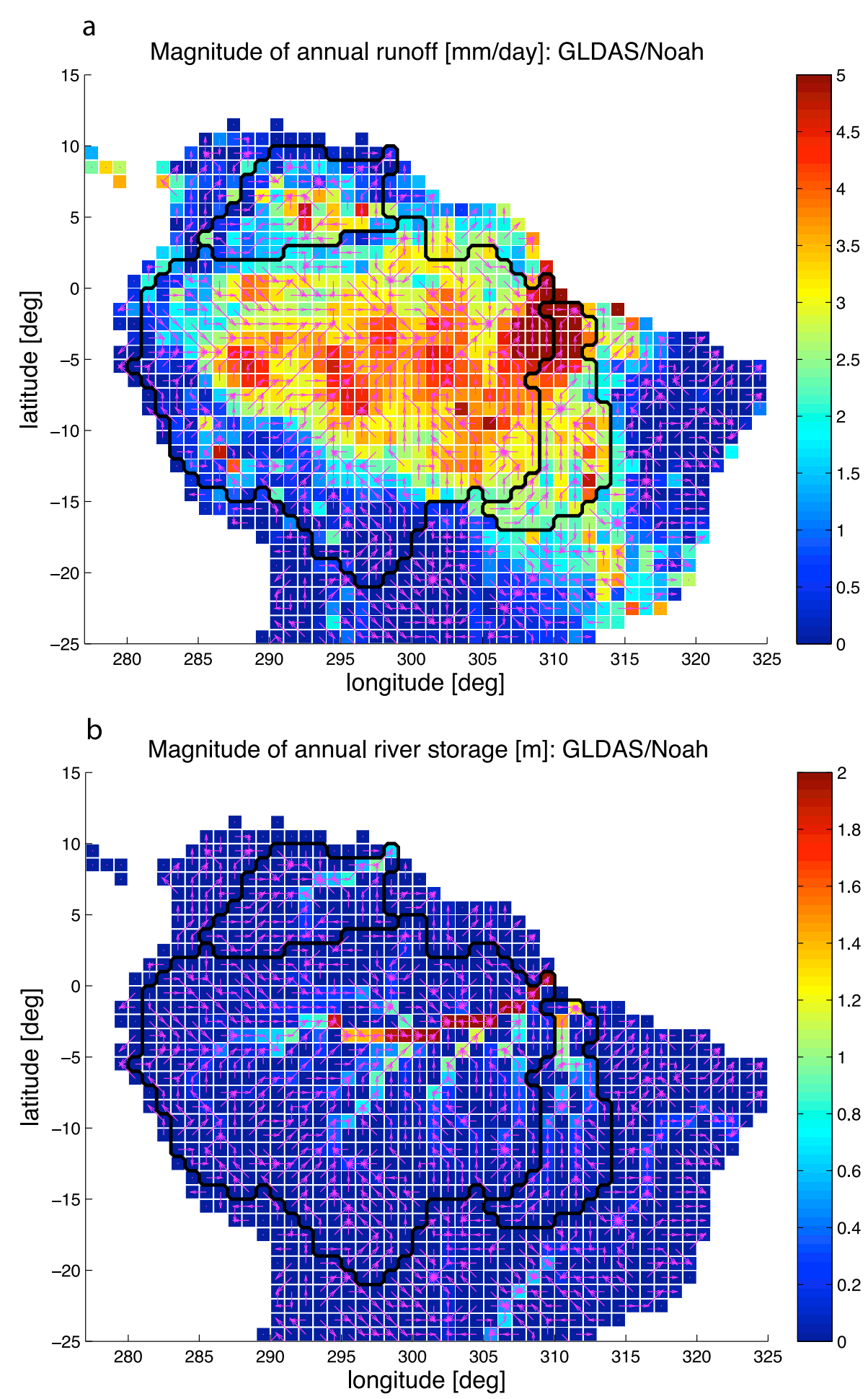

Figure 4. (a) Amplitudes of annual variations for GLDAS/NOAH runoff every $1^{\circ} \times 1^{\circ}$ grid. The arrow indicates the outflow direction used for runoff routing from TRIP. Three major river basins (Amazon, Orinoco, and Tocantins) are delineated. (b) Amplitudes of annual variations for surface water storage computed by routing GLDAS/NOAH runoff with a uniform routing velocity of $30 \mathrm{~cm} / \mathrm{s}$.

soil moisture storage variations and of their difference from the GRACE observations (reflecting surface water storage in addition to errors owing to imperfect soil moisture storage models), respectively. In general, the residual GRACE maps from all LSMs show negatives in the cosine spectrum 

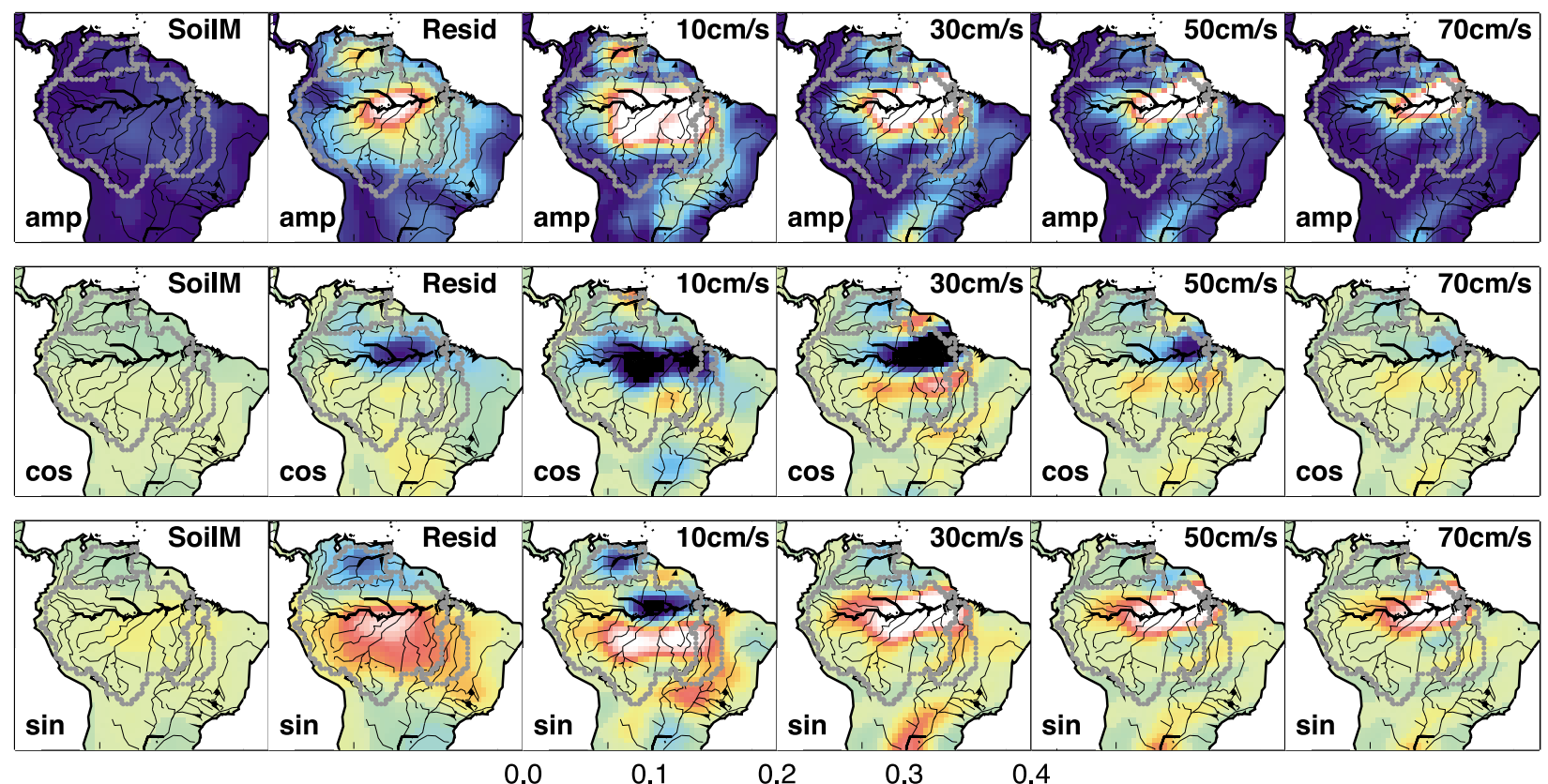

GLDAS/CLM

0.3

0.4 $\mathrm{m}$

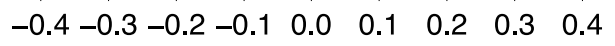
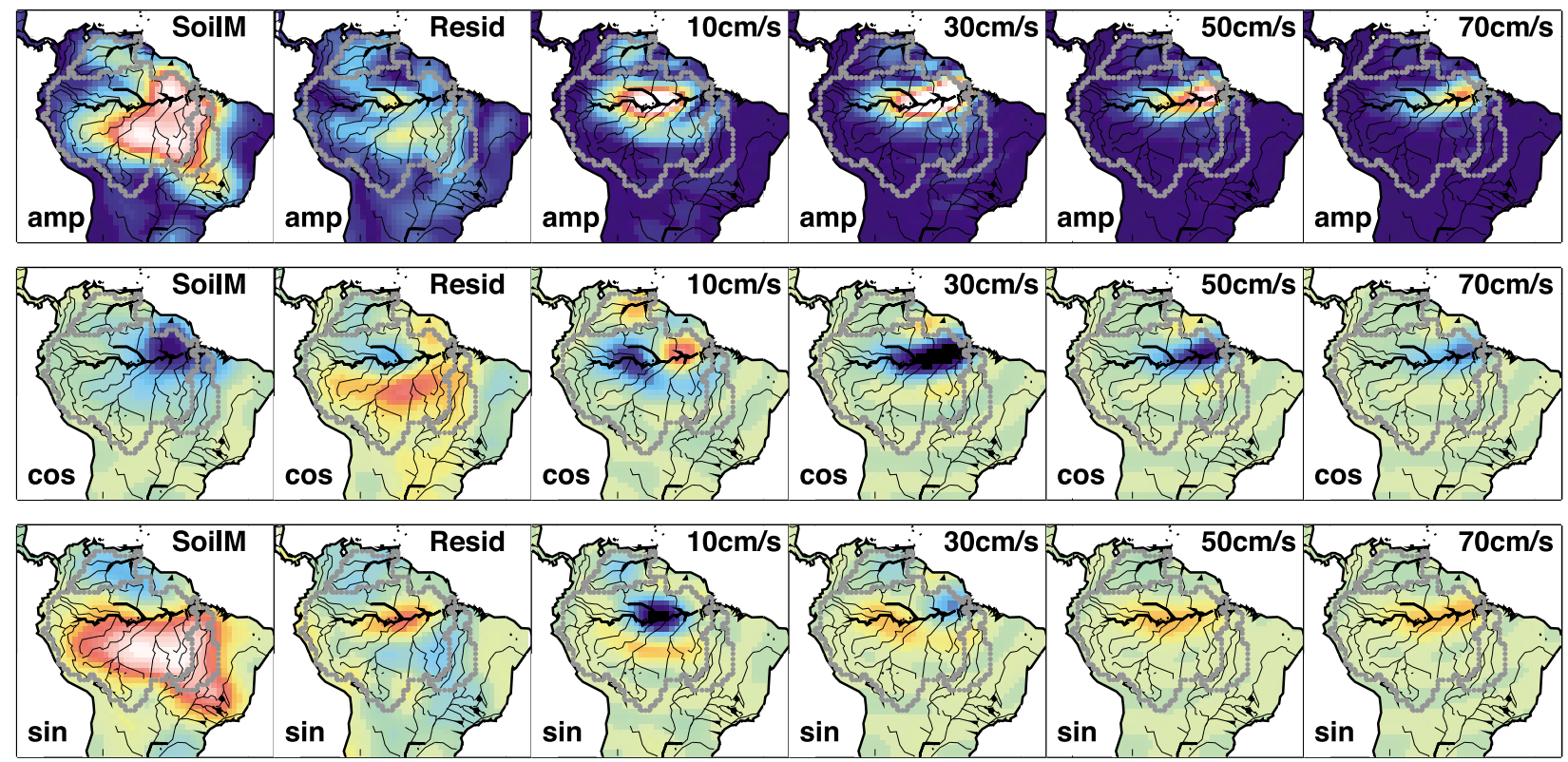

GLDAS/Mosaic

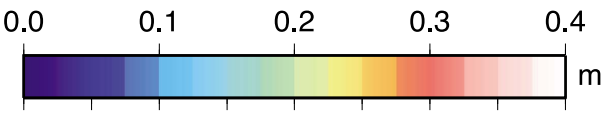

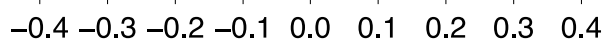

Figure 5. Amplitude, cosine and sine components of the annual cycle in the soil moisture variations (SoilM) from GLDAS/LSMs and the residual GRACE observations (Resid) excluding the modeled soil moisture. Those of the annual cycle in surface water storage computed by runoff routing with various flow velocities of 10, 30, 50, and $70 \mathrm{~cm} / \mathrm{s}$ are presented. The spatial smoothing commensurate with the GRACE observations is applied to the model outputs. The color scale shows the ranges for amplitude $(0-0.4 \mathrm{~m})$ and for cosine and sine components $(-0.4-0.4 \mathrm{~m})$. 

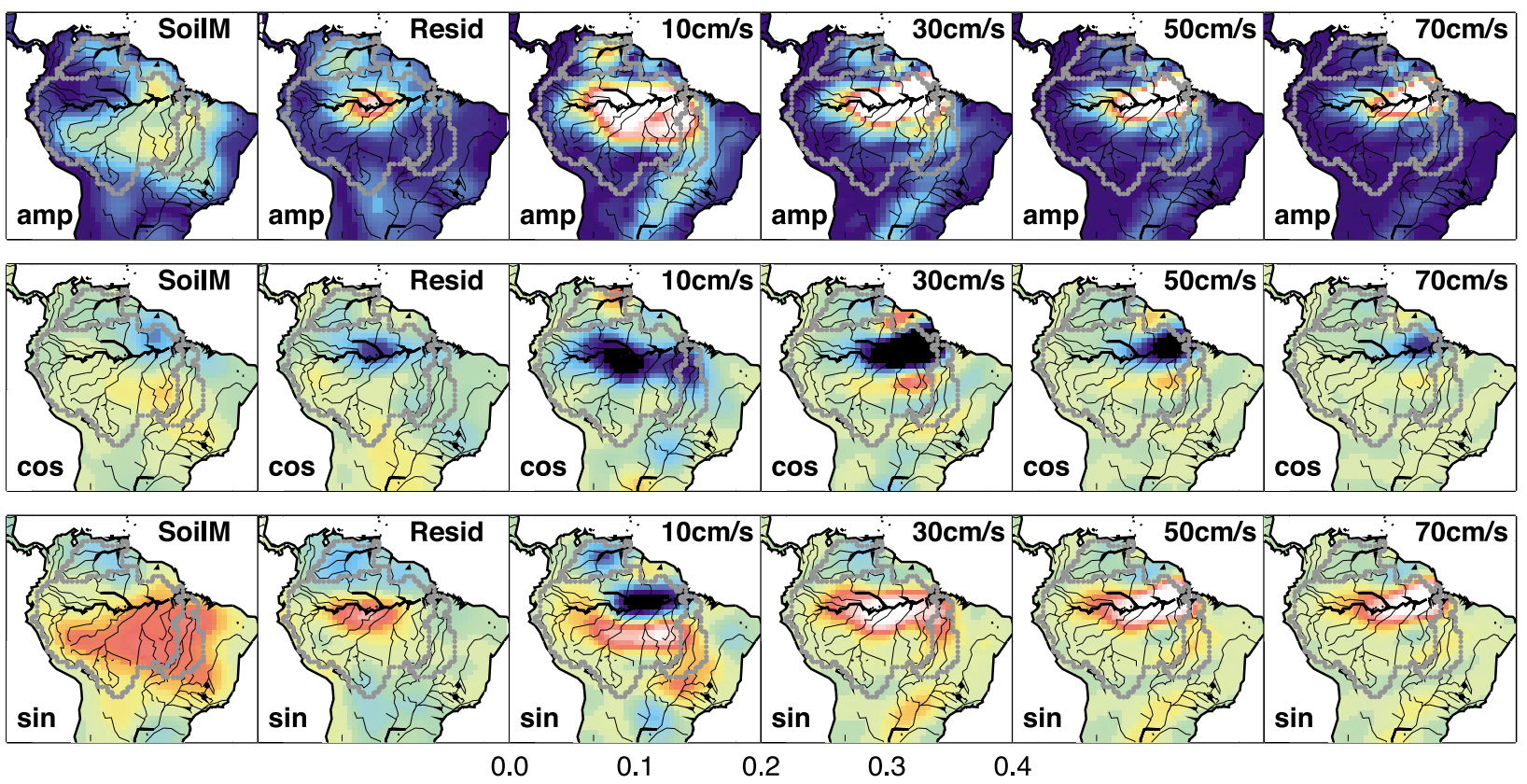

GLDAS/NOAH

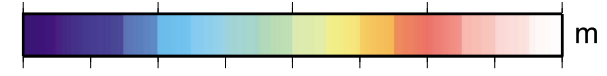

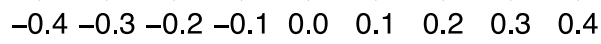
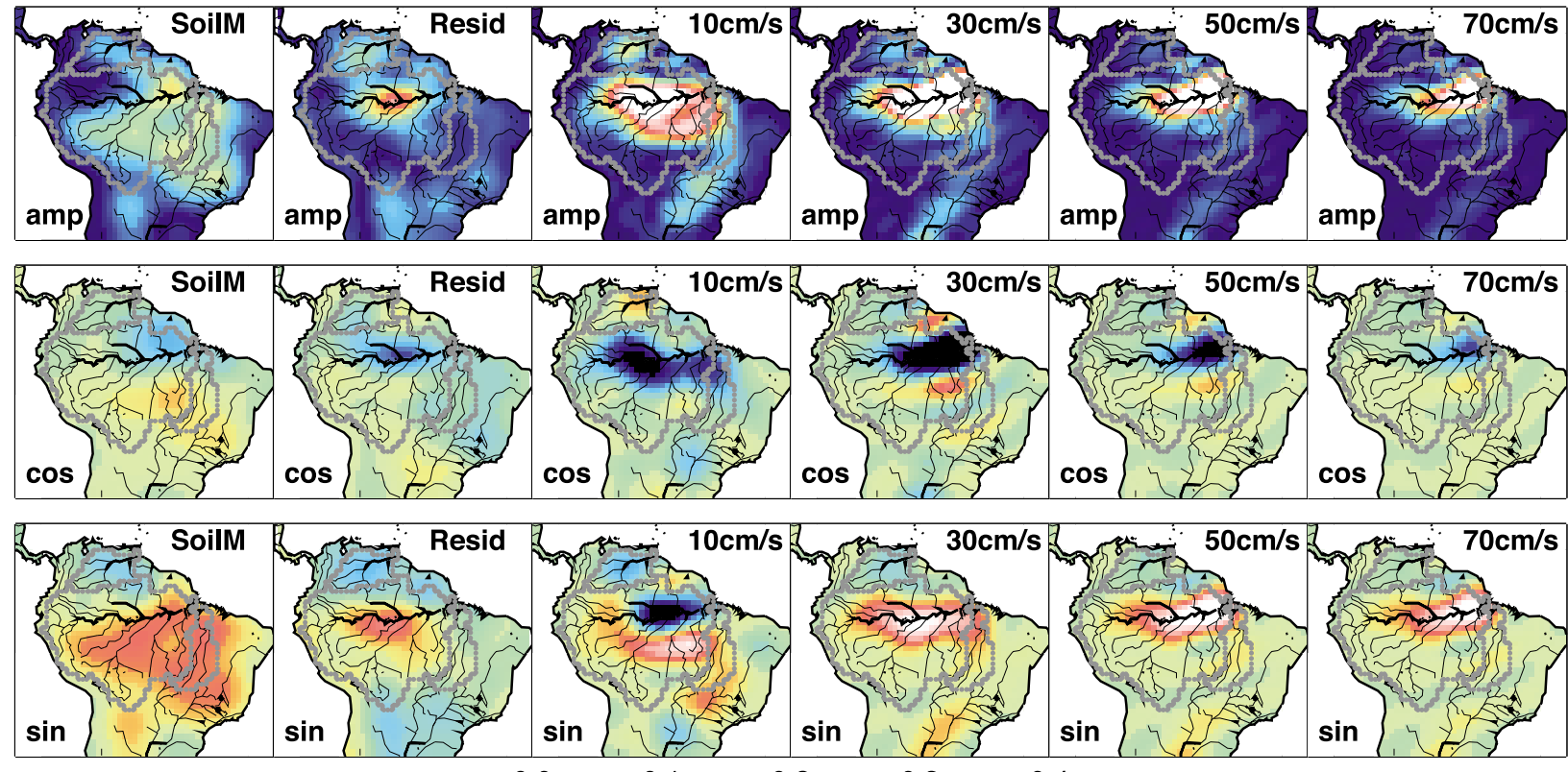

GLDAS/VIC

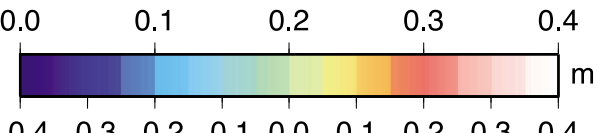

Figure 5. (continued)

(indicating the peak during June-July) and positives in the sine spectrum (implying the peak during March-April) along the Amazon main stem. However, there are substantial differences in magnitudes and spatial patterns among the LSMs. The residuals computed with soil moisture storage from GLDAS/Mosaic show dispersive features occupying the southern Amazon basin with posi- 
tives in the cosine spectrum and negatives in the sine spectrum. Those features are not found from the runoff routing simulations yielding more substantial anomalies along the main stem (not over the southern part of the basin). These residuals are not likely to be associated with the surface water storage, however, and are more likely to be artifacts caused by the over-estimated soil moisture storage from the LSM. The soil moisture storage from GLDAS/CLM is too small to explain the GRACE observations and consequently resulted in too large dispersive anomalies over the southern Amazon basin in the sine coefficient of the residual map. The soil moisture storage outputs from GLDAS/ NOAH and GLDAS/VIC show the most reasonable agreement with the annual cycle of GRACE observations except for the concentrated anomalies along the Amazon main stem, which are likely to be surface water storage not modeled in the LSM.

[20] The surface water storage anomalies are simulated using uniform velocities of $10,30,50$, and $70 \mathrm{~cm} / \mathrm{s}$ for routing surface and sub-surface runoff outputs throughout the each basin (the third, fourth, fifth, and sixth columns of Figure 5, respectively). The routing simulation with a faster velocity tends to make the peak of the annual variation appear further downstream. The overall magnitude of the annual surface water storage decreases with increasing velocity. The simulation with the low velocity such as $10 \mathrm{~cm} / \mathrm{s}$ shows the positives in the southern part and the negatives in the main stem for the sine component. It is due to slow water transport from upstream of the southern tributaries, yet they are not consistent with the observations (the second column 'Resid' in Figure 5). The surface water storage from GLDAS/Mosaic is comparatively smaller than the ones from other LSMs (especially for the sine component) since the runoff from GLDAS/Mosaic is the smallest among the schemes tested. On the other hand, GLDAS/CLM produced the largest surface water storage.

[21] In general, the negative anomalies in the cosine component and the positives in the sine component around the central part of the Amazon main stem from the GRACE observations coincide with the simulations with uniform velocity of $30 \mathrm{~cm} / \mathrm{s}$ or higher. However, the magnitude of the simulated surface water storage is roughly two times larger. The most distinct difference between the model surface water storage and the GRACE observations is found around the Amazon delta. The models show the anomalies prevailing over the entire main stem and getting larger in their magnitudes toward the delta. However, the observations indicate the peak signal at the central Amazon main stem around the city of Manus, not at the downstream.

[22] We also compute the surface water storage by routing the GLDAS/NOAH runoff outputs with spatially variable velocities. The discharge would gradually increase downstream while the observed surface water storage presents the peak at the midstream and decreases downstream owing to the largest floodplain that stores the greatest amount of water around the Manaus. It indicates velocity should increase downstream because the discharge is proportional to the product of storage and velocity. We model the effective velocity with $u_{0}$ (i.e., $30 \mathrm{~cm} / \mathrm{s}$ ) for all upstream grids of a certain grid, while the velocity for the downstream grids increases linearly through

$$
u\left(u_{0}, s, d_{0}\right)=u_{0}+s\left(d-d_{0}\right), \text { if } d \geq d_{0},
$$

where $s$ is the rate of velocity (i.e., acceleration), $d$ is a distance to the respective grid where the velocity is assigned with $u$ from the upper most grid along the main stem, $d_{0}$ is $d$ at a unknown grid where the velocity starts to increase (or where the flow starts to accelerate). Each simulation with given $s$ and $d_{0}$ is compared with the GRACE observations and the variance reduction (VR) coefficient is computed as

$$
\begin{aligned}
& V R_{j}(\mathbf{u})=1 \\
& -\frac{\left(\mathbf{Y}_{j}-\mathbf{S}_{j}-\left[\mathbf{G}_{j}(\mathbf{u})\right]^{-1} \mathbf{Q}_{j}\right)^{T}\left(\mathbf{Y}_{j}-\mathbf{S}_{j}-\left[\mathbf{G}_{j}(\mathbf{u})\right]^{-1} \mathbf{Q}_{j}\right)}{\left(\mathbf{S}_{j}+\left[\mathbf{G}_{j}(\mathbf{u})\right]^{-1} \mathbf{Q}_{j}\right)^{T}\left(\mathbf{S}_{j}+\left[\mathbf{G}_{j}(\mathbf{u})\right]^{-1} \mathbf{Q}_{j}\right)}
\end{aligned}
$$

where $\mathbf{Y}_{j}$ is a vector consisting of the annual Fourier spectrum of the GRACE observations. u contains the spatially variable velocity field computed using equation (5). The VR coefficient essentially indicates how good the models fit to the observations, so that VR $=1$ implies a perfect agreement between the model and observation.

[24] Figure 6 presents the VR for various choices of the velocity rate $(s)$ and the downstream distance from the city of Manaus $\left(d-d_{0}\right)$. In all cases, $u_{0}$ was fixed as $30 \mathrm{~cm} / \mathrm{s}$. The fit to the observations can be substantially improved from 0.4 to 0.7 in VR by implementing increasing velocity downstream instead of using a uniform velocity. The maximum VR occurs when the flow velocity starts to increase from the city of Manaus by $10-15 \mathrm{~cm} / \mathrm{s}$ every $110 \mathrm{~km}$ in a downstream direction, resulting 


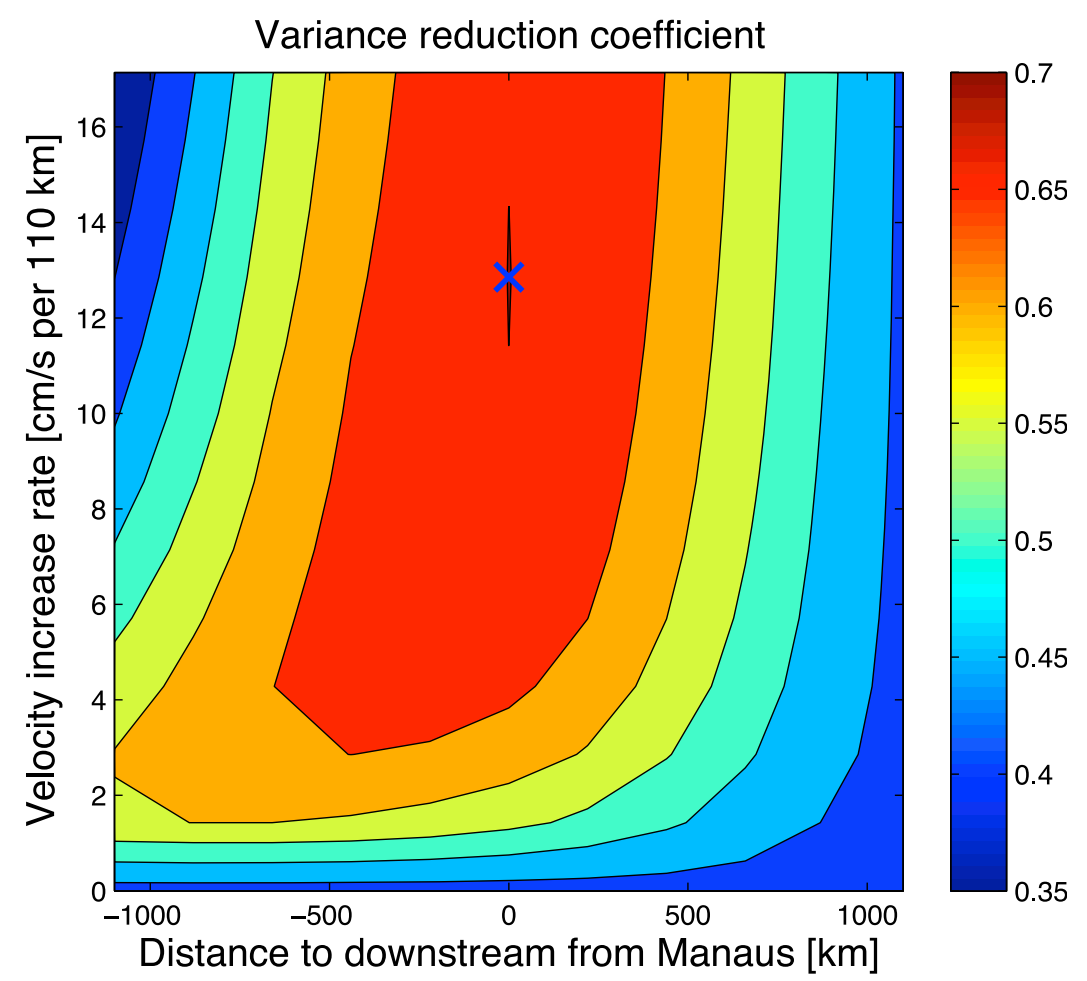

Figure 6. Variance reduction coefficient computed from the GRACE observations and various simulations of runoff and soil moisture outputs of GLDAS/NOAH. The abscissa indicates the location where in the main stem the flow velocity starts to increase from $30 \mathrm{~cm} / \mathrm{s}$. The zero indicates the city of Manaus. The positive and negative indicates downstream and upstream from Manaus, respectively. The ordinate shows the rate of the flow velocity. The cross indicates the optimal case for the location and velocity rate.

in a flow velocity of $130-180 \mathrm{~cm} / \mathrm{s}$ near the Amazon delta. Independently, Richey et al. [1989a] obtained the decreasing residence time (inverse of velocity) of the flood wave downstream after the Manacapuru gauging station close to the Manaus. The progressively increasing velocity in a downstream direction reduces the amplitude of surface water storage anomalies in downstream grids as indicated in Figure 7a. Compared to the case of a uniform velocity (Figure $4 b$ ), the increasing trend in the amplitude of surface water storage downstream disappears. The peak anomalies occur around the central main stem. The difference in surface water storage between the uniform velocity and variable velocities is shown in Figure 7b. Note that we increase the flow velocity downstream for the Araguaia/Tocantins rivers in addition to the Amazon river. At the GRACE spatial resolution, the surface water storage simulated with variable velocities is shown in Figure 8. The location of the peak anomaly agrees better with the GRACE observations. In particular, the cosine component of the annual variation is improved substantially, agreeing with the GRACE observations in its magnitude and spatial pattern. The sine component of the model is still larger in magnitude than the observation.

\section{Comparison With the Ground Gauge Records}

[25] In addition to the space-based large-scale observations, we use the discharge measurements recorded at ground gauging station to compare with the discharge outputs from various model simulations. The long-term mean historical (back to the early 1900s) and monthly discharge data, such as in the work by Richey et al. [1989b], at various locations are available through the Website (http:// www.sage.wisc.edu/riverdata/). We compare the data at the Obidos station since they are most comprehensive covering several decades of monthly mean records and reflect the routed water from majority of upstream tributaries including the Negro, Purus, Jupura, Madeira and Solimoes, but excluding the Tapajos and Xingo.

[26] Figure 9 shows the monthly variations of the observed discharge and its annual component with 

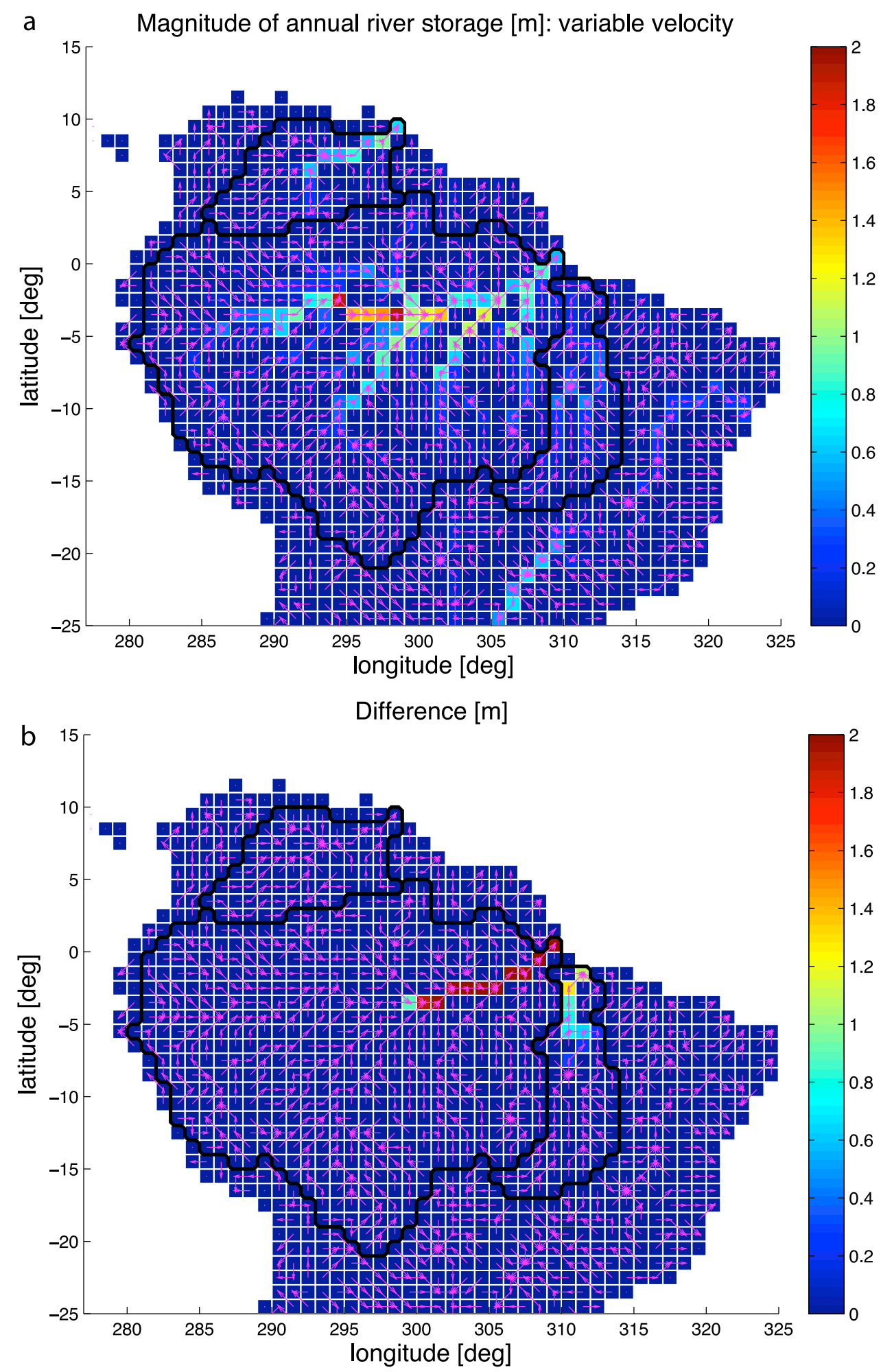

Figure 7. (a) Amplitudes of the annual variations for surface water storage computed by routing GLDAS/NOAH runoff with spatially variable routing velocities. The velocities at downstream region of the Amazon main stem, Araguaia and Tocantins rivers are increased. (b) The difference of the simulations from spatially variable velocities and a uniform velocity (i.e., difference between Figures $7 \mathrm{a}$ and $4 \mathrm{~b}$ ). 


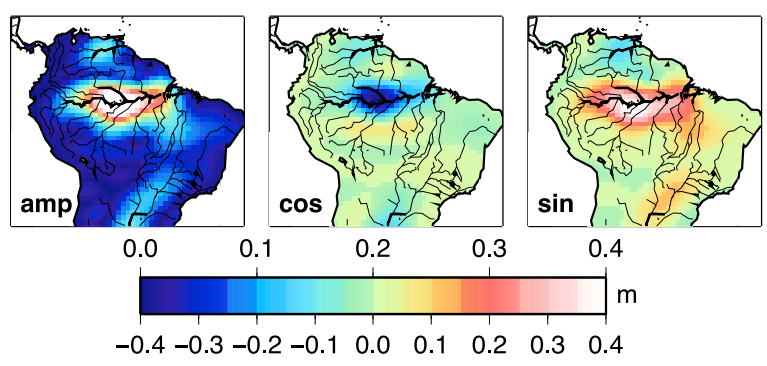

Figure 8. Amplitude, cosine and sine components of the annual cycle in surface water storage computed by routing GLDAS/NOAH runoff with spatially variable flow velocities (same as Figure 7a), but after applying the spatial smoothing commensurate with the GRACE observations. The color scale shows the ranges for amplitude $(0-0.4 \mathrm{~m})$ and for cosine and sine components $(-0.4-0.4 \mathrm{~m})$.
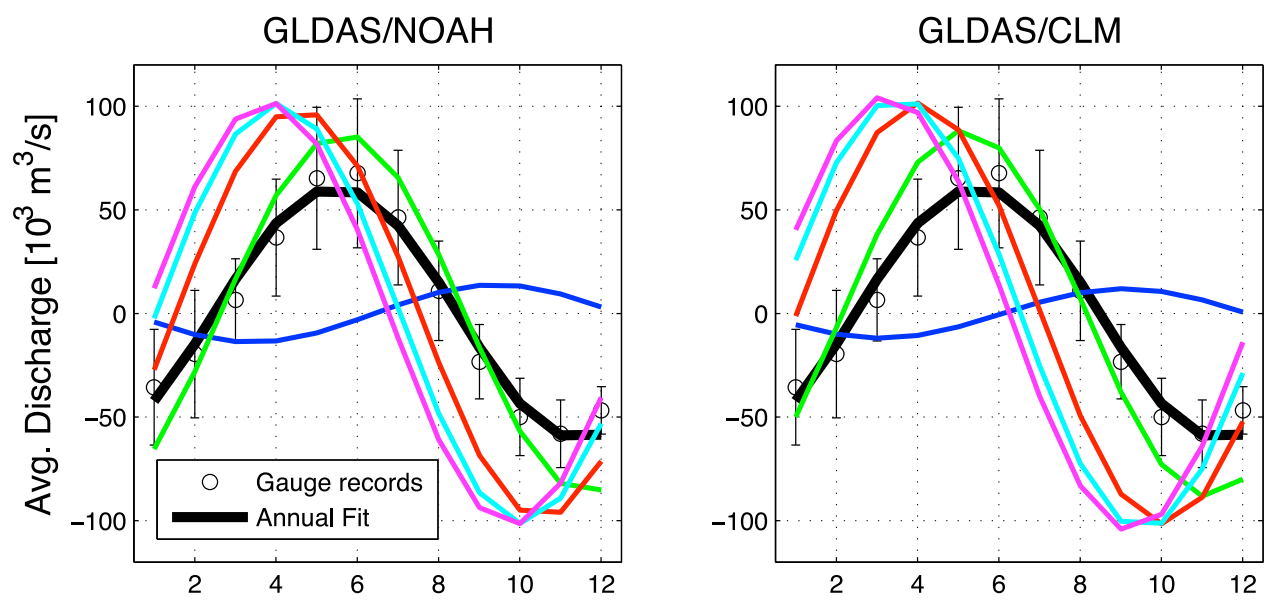

Sta.: Obidos (2S/304.5E), Riv.: Amazonas
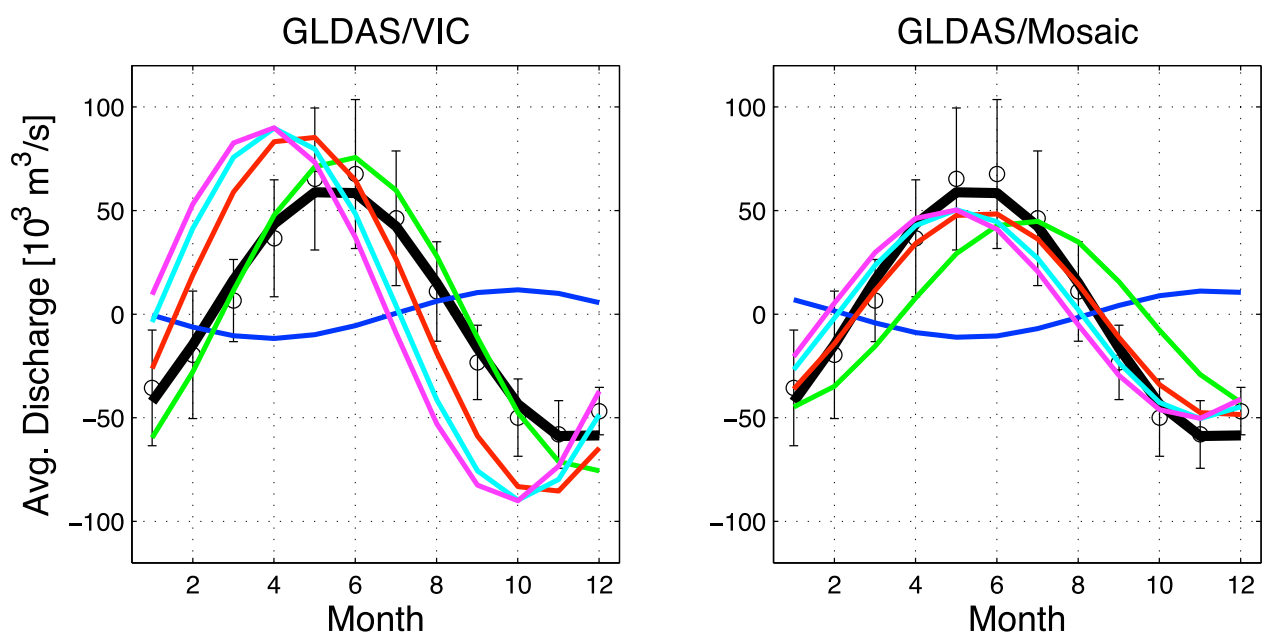

Figure 9. Long-term mean monthly discharge data at the Obidos gauge station located at $1.9^{\circ} \mathrm{S}$ and $304.5^{\circ} \mathrm{E}$ (circle) and the annual cycle (black line). The error bar indicates the year-to-year variation in each month. The mean value of discharge is removed. The annual cycles of model discharge by routing the runoff outputs from GLDAS/NOAH, CLM, VIC, and Mosaic, with various velocities of 10,30,50,70, and $90 \mathrm{~cm} / \mathrm{s}$ are shown in blue, green, red, cyan, and magenta, respectively. 


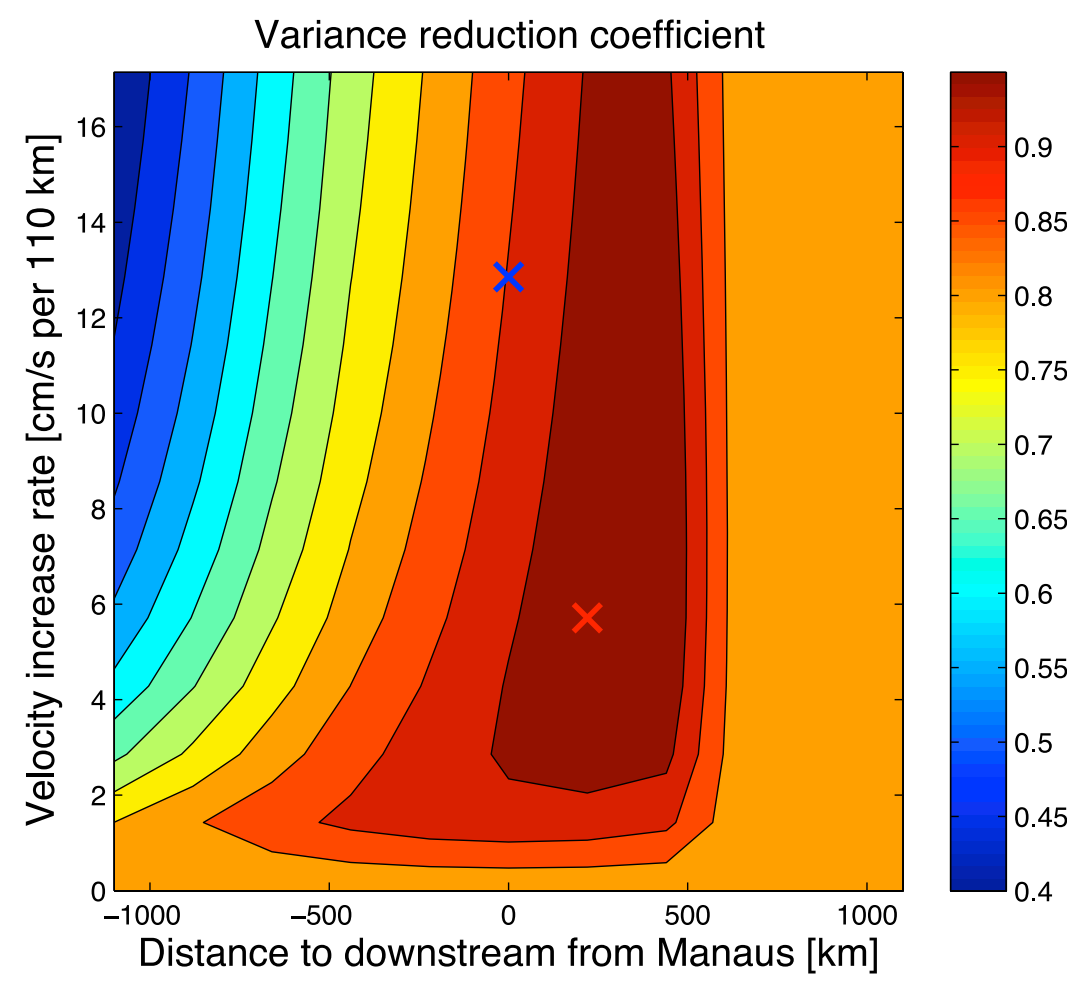

Figure 10. As in Figure 6 but based on discharge measurements at the Obidos station. The blue and red crosses are the optimal cases obtained from the GRACE and discharge data, respectively.

NOAH, CLM and VIC and smaller in Mosaic. It is consistent with the analysis indicated from the GRACE observations.

[27] We compute the VR coefficients of the discharge data by implementing spatially varying velocities in the routing models, just like we have done with the GRACE data. Again, we try to adjust two parameters indicating the velocity increase rate and the location where the acceleration starts. As shown in Figure 10, the agreement of the models to the discharge measurements at Obidos increases from 0.8 to 0.95 or higher in the VR coefficients when the flow velocity increases downstream. The optimized set for those two parameters from the GRACE data gives 0.9 on the VR coefficient, when compared to gauge measurements. Both spaceborne and ground data indicate the increase of the velocity starting around the Manaus or its adjacent areas. Figure 11 shows the discharge time series from the gauge measurement and three routing models of GLDAS/NOAH runoff outputs with an uniform $30 \mathrm{~cm} / \mathrm{s}$ velocity and the optimized velocity fields from the GRACE and gauge data. The discharge model generated by the two parameters optimized with the GRACE data yields a slightly earlier arrival of the peak than the mea- surement and than the model optimized with the gauge data, but yet, a better agreement than the uniform velocity model.

[28] The actual velocity field should be much more complex than the model described only by the two parameters we introduce in equation (5). More advanced routing methods implementing the kinematic, diffusive, and full dynamic waves should be implemented to acquire physically meaningful velocity fields, and thus eventually to assess the LSM runoff simulation more accurately.

\section{Summary and Discussion}

[29] The GRACE satellite observations of mass redistribution (time-variable gravity) are exploited to analyze water storage around the Amazon basin. A simple yet effective method for runoff routing is implemented to compute mass change of surface water (river and floodplain storage) in addition to soil moisture storage available directly from the LSM. The spatial distribution of the annual change in soil moisture anomaly is distinct from that of the runoff-generated water flow. The former is more dispersive over the entire basin with moderate 


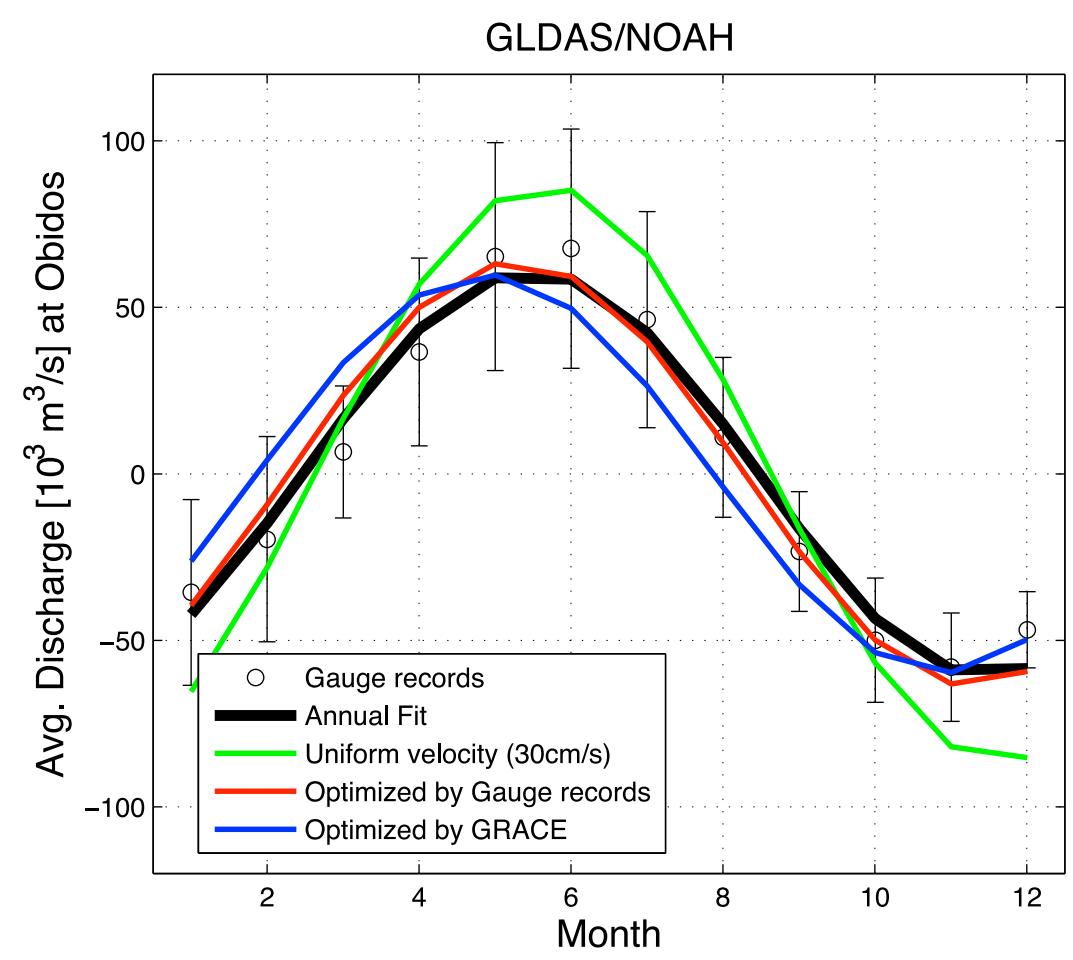

Figure 11. As in Figure 9 but including the runoff routing simulations with variable velocities, optimized with the GRACE and discharge data.

magnitude $(\sim 25 \mathrm{~cm})$, while the latter is intense ( $\sim 40 \mathrm{~cm}$ or larger) but significant only over the rivers and floodplains. However, the total storages of soil moisture and surface water over the entire basin remain similar. We find that the GRACE observations are in agreement mostly with GLDAS/NOAH and GLDAS/VIC soil moisture storage particularly over the upstream of the southern tributaries. The disagreement between the observations and soil moisture storage models appears mostly along the Amazon main stem. However, GLDAS/CLM (version 2) and GLDAS/ Mosaic soil moisture storages are too little and too much, respectively, compared to the GRACE observations, eventually resulting in overestimated and underestimated runoff, respectively.

[30] In general, the surface water storage models are found to be larger than the GRACE measurements. The peak surface water storage anomaly is observed around the midstream of the Amazon main stem. It does not appear around the downstream or the delta, where the routing simulations present the peak amplitude of surface water when a uniform velocity is used. We deduce the following hypotheses to explain such differences:

[31] First, the incorrect seasonal precipitation may have the direct consequence of overestimated sea- sonal change in runoff and thus surface water storage.

[32] Second, there might be some limitation in the GLDAS/LSM regarding the precipitation partitioning into ET and runoff (likely to be associated with the leaf area index parameter). As studied by Koster and Milly [1997], the runoff process in a LSM cannot be improved without accurate modeling of ET since these two fluxes are substantially inter-related. For GLDAS/NOAH and GLDAS/ VIC, the seasonal cycle of runoff outputs are very large exceeding $5 \mathrm{~mm} /$ day particularly around the Amazon delta. On the contrary, ET shows very small seasonal variation $(\sim 0.5 \mathrm{~mm} /$ day and less $)$ throughout the basin. The possible excess in the runoff (due to insufficient ET) especially near the delta may cause the peak anomaly of surface water storage to be located too far downstream.

[33] Third, our runoff routing simulation does not account for evaporation and infiltration to groundwater during surface water transport to the ocean, which may explain in part the fact that the simulation results are larger in magnitude than the observations. The model simulations therefore give the upper bound of the surface water storage since all runoffs are delivered to the outlet without any mass loss during routing. 
[34] Fourth, the routing with spatially and temporally variable velocities may be important even for large-scale modeling. The storage gradually increases downstream when the uniform velocity is used. The Manning's equation indicates the increasing velocity proportional to $h^{2 / 3}$, where $h$ is storage height, when a rectangular cross section is assumed at a large spatial scale. The increasing flow velocity downstream, as also indicated by Costa and Foley [1997] and Coe et al. [2008], indeed helps reconcile the surface water storage simulation with the GRACE measurements over the entire basin and with the discharge measurements at Obidos. Such variable velocity fields can be simulated by implementing the diffusive and/or kinematic waves as done by Trigg et al. [2009] and Beighley et al. [2009], but for the large-scale modeling. They would be particularly important and may help explain the backwater effects observed around the major tributaries [Meade et al., 1991].

[35] The time-variable satellite gravity observations over the Amazon demonstrate the inadequacy of the LSM water cycle components and of a simple routing method based on the continuity equation. A more advanced approach reflecting aforementioned effects should be implemented for runoff routing within the river network. Temporally and spatially variable velocities, as also indicated by Han et al. [2009], separate routings of surface and sub-surface runoffs, implementation of momentum conservation, and interaction between fast moving main channels and slow moving floodplain zones need to be explored. Improved routing models will help to validate the runoff outputs from LSM better. Furthermore, the intricate relationship of ET with runoff within the LSM suggests an importance of analyzing runoff to assess ET that is more difficult to measure [Koster and Milly, 1997; Costa and Foley, 1997]. The quality of ET output from an LSM can be inferred indirectly by the quality of runoff output, for example, as in the work by Mocko and Sud [1998]. Therefore, when analyzed with the advanced routing methods as well as the GRACE data, the soil moisture, runoff, and ET parameters in a LSM can be validated and analyzed properly. The specific results based on satellite data for surface water storage and flow velocities in the Amazon basin will provide unique observation-based information on the Amazon water cycles and are of immediate relevance for improving surface routing schemes and quantification of water cycle parameters in large-scale land surface models.

\section{Acknowledgments}

[36] This work was supported by NASA GRACE projects and the Earth Surface and Interior program. Scott Luthcke and David Rowlands are acknowledged for computing the precise orbits of the GRACE satellites. We would like to thank the German Space Operations Center of the German Aerospace Center, DLR, for providing continuously and nearly $100 \%$ of the raw telemetry data of the twin GRACE satellites. JPB is currently visiting NASA Goddard Space Flight Center with a Marie Curie International Outgoing Fellowship (PIOF-GA2008-221753). The comments from anonymous reviewers helped to improve the manuscript.

\section{References}

Alsdorf, D., P. Bates, J. Melack, M. Wilson, and T. Dunne (2007), Spatial and temporal complexity of the Amazon flood measured from space, Geophys. Res. Lett., 34, L08402, doi:10.1029/2007GL029447.

Beighley, R. E., K. G. Eggert, T. Dunne, Y. He, V. Gummadi, and K. L. Verdin (2009), Simulating hydrologic and hydraulic processes throughout the Amazon River Basin, Hydrol. Processes, 23, 1221-1235, doi:10.1002/hyp.7252.

Bonan, G. B. (1998), The land surface climatology of the NCAR land surface model coupled to the NCAR Community Climate Model, J. Clim., 11, 1307-1326, doi:10.1175/ 1520-0442(1998)011<1307:TLSCOT>2.0.CO;2.

Chen, F., K. Mitchell, J. Schaake, Y. K. Xue, H. L. Pan, V. Koren, Q. Y. Duan, M. Ek, and A. Betts (1996), Modeling of land surface evaporation by four schemes and comparison with FIFE observations, J. Geophys. Res., 101(D3), 7251-7268, doi:10.1029/95JD02165.

Coe, M. T. (2000), Modeling terrestrial hydrological systems at the continental scale: Testing the accuracy of an atmospheric GCM, J. Clim., 13(4), 686-704, doi:10.1175/15200442(2000)013<0686:MTHSAT>2.0.CO;2.

Coe, M. T., M. H. Costa, and E. A. Howard (2008), Simulating the surface waters of the Amazon River basin: Impacts of new river geomorphic and flow parameterizations, Hydrol. Processes, 22(14), 2542-2553, doi:10.1002/hyp.6850.

Costa, M. H., and J. A. Foley (1997), Water balance of the Amazon Basin: Dependence on vegetation cover and canopy conductance, J. Geophys. Res., 102(D20), 23,973-23,989, doi:10.1029/97JD01865.

Costa, M. H., J. C. Souza-Filho, and A. Ribeiro (2004), Comments on "The regional evapotranspiration of the Amazon," J. Hydrometeorol., 5, 1279-1280

Güntner, A. (2008), Improvement of global hydrological models using GRACE data, Surv. Geophys., doi:10.1007/s10712-0089038-y.

Hagemann, S., and L. Dümenil (1997), A parameterization of lateral water flow for the global scale, Clim. Dyn., 14, 17-31, doi:10.1007/s003820050205.

Han, S.-C., D. D. Rowlands, S. B. Luthcke, and F. G. Lemoine (2008), Localized analysis of satellite tracking data for studying time-variable Earth's gravity fields, J. Geophys. Res., 113, B06401, doi:10.1029/2007JB005218.

Han, S.-C., H. Kim, I.-Y. Yeo, P. Yeh, T. Oki, K.-W. Seo, D. Alsdorf, and S. B. Luthcke (2009), Dynamics of surface water storage in the Amazon inferred from measurements of inter-satellite distance change, Geophys. Res. Lett., 36, L09403, doi:10.1029/2009GL037910. 
Hansen, J., G. Russell, D. Rind, P. Stone, A. Lacis, S. Lebedeff, R. Reudy, and L. Travis (1983), Efficient three-dimensional global models for climate studies: Models I and II, Mon. Weather Rev., 111, 609-662, doi:10.1175/1520-0493(1983)111< 0609:ETDGMF $>2.0 . \mathrm{CO} ; 2$

Hunger, M., and P. Döll (2008), Value of river discharge data for global-scale hydrological modeling, Hydrol. Earth Syst. Sci., 12, 841-861, doi:10.5194/hess-12-841-2008.

Kato, H., M. Rodell, F. Beyrich, H. Cleugh, E. van Gorsel, H. Z. Liu, and T. P. Meyers (2007), Sensitivity of land surface simulations to model physics, land characteristics, and forcings, at four CEOP sites, J. Meteorol. Soc. Jpn., 85A, 187-204, doi:10.2151/jmsj.85A.187.

Kim, H., P. J.-F. Yeh, T. Oki, and S. Kanae (2009), Role of rivers in the seasonal variations of terrestrial water storage over global basins, Geophys. Res. Lett., 36, L17402, doi:10.1029/ 2009GL039006.

Koster, R. D., and P. C. Milly (1997), The interplay between transpiration and runoff formulations in land surface schemes used with atmospheric models, J. Clim., 10, 1578-1591, doi:10.1175/1520-0442(1997)010<1578:TIBTAR>2.0.CO;2.

Koster, R. D., and M. J. Suarez (1996), Energy and water balance calculations in the Mosaic LSM, NASA Tech. Memo., 104606, vol. 9, 59 pp.

Liang, X., D. P. Lettenmaier, E. F. Wood, and S. J. Burges (1994), A simple hydrologically based model of land surface water and energy fluxes for general circulation models, J. Geophys. Res., 99, 14,415-14,428, doi:10.1029/94JD00483.

Luthcke, S. B., D. D. Rowlands, F. G. Lemoine, S. M. Klosko, D. Chinn, and J. J. McCarthy (2006), Monthly spherical harmonic gravity field solutions determined from GRACE inter-satellite range-rate data alone, Geophys. Res. Lett., 33, L02402, doi:10.1029/2005GL024846.

Meade, R. H., J. M. Rayol, S. C. Conceicao, and J. R. G. Natividade (1991), Backwater effects on the Amazon River basin of Brazil, Environ. Geol. Water Sci., 18, 105-114, doi:10.1007/BF01704664.

Miller, J. R., G. L. Russell, and G. Caliri (1994), Continentalscale river flow in climate models, J. Clim., 7, 914-928, doi:10.1175/1520-0442(1994)007<0914:CSRFIC >2.0.CO;2.

Mocko, D. M., and Y. C. Sud (1998), Comparison of a land surface model (SSiB) to three parameterizations of evapotranspiration - A study based on ISLSCP Initiative I data, Earth Interact., 2(3), 1-35, doi:10.1175/1087-3562(1998)002< 0001:COALSM $>2.3 . \mathrm{CO} ; 2$.

Oki, T., T. Nishimura, and P. Dirmeyer (1999), Assessment of annual runoff from land surface models using Total Runoff
Integrating Pathways (TRIP), J. Meteorol. Soc. Jpn., 77, 235-255.

Olivera, F., J. Famiglietti, and K. Asante (2000), Global-scale flow routing using a source-to-sink algorithm, Water Resour. Res., 36(8), 2197-2207, doi:10.1029/2000WR900113.

Pitman, A. J. (2003), The evolution of, and revolution in, land surface schemes designed for climate models, Int. J. Climatol., 23, 479-510, doi:10.1002/joc.893.

Ramillien, G., F. Frappart, A. Güntner, T. Ngo-Duc, A. Cazenave, and K. Laval (2006), Time variations of the regional evapotranspiration rate from Gravity Recovery and Climate Experiment (GRACE) satellite gravimetry, Water Resour. Res., 42, W10403, doi:10.1029/2005WR004331.

Ray, R. D. (1999), A global ocean tide model from TOPEX/ POSEIDON altimetry: GOT99.2, NASA Tech. Memo. 1999-209478.

Richey, J. E., et al. (1989a), Source and routing of the Amazon river flood wave, Global Biogeochem. Cycles, 3, 191-204, doi:10.1029/GB003i003p00191.

Richey, J. E., C. Nobre, and C. Deser (1989b), Amazon River discharge and climate variability: 1903 to 1985, Science, 246, 101-103, doi:10.1126/science.246.4926.101.

Rodell, M., et al. (2004), The Global Land Data Assimilation System, Bull. Am. Meteorol. Soc., 85, 381-394, doi:10.1175/ BAMS-85-3-381.

Shuttleworth, W. J. (1988), Evaporation from Amazonian rainforest, Proc. R. Soc. London, 233, 321-346, doi:10.1098/ rspb.1988.0024.

Syed, T. H., J. S. Famiglietti, M. Rodell, J. Chen, and C. R. Wilson (2008), Analysis of terrestrial water storage changes from GRACE and GLDAS, Water Resour. Res., 44, W02433, doi:10.1029/2006WR005779.

Tapley, B. D., et al. (2005), GGM02-An improved Earth gravity field model from GRACE, J. Geod., 79, 467-478, doi:10.1007/s00190-005-0480-Z

Trigg, M. A., M. D. Wilson, P. D. Bates, M. S. Horritt, D. E. Alsdorf, B. R. Forsberg, and M. C. Vega (2009), Amazon flood wave hydraulics, J. Hydrol., 374, 92-105, doi:10.1016/ j.jhydrol.2009.06.004.

Werth, D., and R. Avissar (2004), The regional evapotranspiration of the Amazon, J. Hydrometeorol., 5, 100-109.

Zaitchik, B. F., M. Rodell, and F. Olivera (2010), Evaluation of the Global Land Data Assimilation System using global river discharge data and a source-to-sink routing scheme, Water Resour. Res., 46, W06507, doi:10.1029/2009WR007811. 